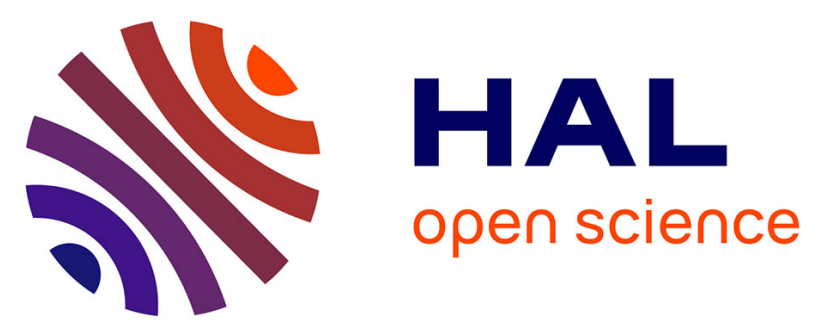

\title{
Genetic variation in host-specific competitiveness of the symbiont Rhizobium leguminosarum symbiovar viciae
} Stéphane Boivin, Frederic Mahé, Frederic Debellé, Marjorie Prevent, Mathilde Tancelin, Marc Tauzin, Jerzy Wielbo, Sylvie Mazurier, Peter Young, Marc Lepetit

\section{To cite this version:}

Stéphane Boivin, Frederic Mahé, Frederic Debellé, Marjorie Prevent, Mathilde Tancelin, et al.. Genetic variation in host-specific competitiveness of the symbiont Rhizobium leguminosarum symbiovar viciae. Frontiers in Plant Science, 2021, 12, 10.22541/au.159237007.72934061 . hal-02967193v2

\section{HAL Id: hal-02967193 \\ https://hal.inrae.fr/hal-02967193v2}

Submitted on 20 Jan 2022

HAL is a multi-disciplinary open access archive for the deposit and dissemination of scientific research documents, whether they are published or not. The documents may come from teaching and research institutions in France or abroad, or from public or private research centers.
L'archive ouverte pluridisciplinaire HAL, est destinée au dépôt et à la diffusion de documents scientifiques de niveau recherche, publiés ou non, émanant des établissements d'enseignement et de recherche français ou étrangers, des laboratoires publics ou privés.

\section{(ㄷ)(1)}

Distributed under a Creative Commons Attribution| 4.0 International License 


\section{OPEN ACCESS}

Edited by:

Attila Kereszt, Institute of Plant Biology, Biological

Research Centre, Eötvös Loránd

Research Network, Hungary

Reviewed by:

Alice Checcucci,

University of Bologna, Italy Jose Palacios,

Polytechnic University of Madrid,

Spain

${ }^{*}$ Correspondence: Marc Lepetit marc.lepeti@@inrae.fr

Specialty section:

This article was submitted to Plant Symbiotic Interactions,

a section of the journal

Frontiers in Plant Science

Received: 03 June 2021

Accepted: 29 July 2021 Published: 08 September 2021

Citation:

Boivin S, Mahé F, Debellé $F$ Pervent M, Tancelin M, Tauzin M, Wielbo J, Mazurier S, Young P and Lepetit M (2021) Genetic Variation in Host-Specific Competitiveness of the Symbiont Rhizobium leguminosarum Symbiovar viciae.

Front. Plant Sci. 12:719987.

doi: $10.3389 /$ fpls.2021.719987

\section{Genetic Variation in Host-Specific Competitiveness of the Symbiont Rhizobium leguminosarum Symbiovar viciae}

\author{
Stéphane Boivin ${ }^{1}$, Frederic Mahé2 ${ }^{2}$ Frédéric Debellé ${ }^{3}$, Marjorie Pervent ${ }^{1}$, \\ Mathilde Tancelin ${ }^{1}$, Marc Tauzin ${ }^{1}$, Jerzy Wielbo ${ }^{4}$, Sylvie Mazurier ${ }^{5}$, Peter Young ${ }^{6}$ and \\ Marc Lepetit ${ }^{1,7 *}$

\begin{abstract}
' Laboratoire des Symbioses Tropicales et Méditerranéennes, INRAE, IRD, CIRAD, Montpellier SupAgro, University of Montpellier, Montpellier, France, ${ }^{2}$ Biologie et Génétique des Interactions Plante-Parasite, CIRAD, INRAE, Montpellier SupAgro, University of Montpellier, Montpellier, France, ${ }^{3}$ Laboratoire des Interactions Plantes-Microorganismes, INRAE, CNRS, University of Toulouse, Castanet-Tolosan, France, ${ }^{4}$ Department of Genetics and Microbiology, Maria Curie-Skłodowska University, Lublin, Poland, ${ }^{5}$ Agroecology, AgroSup Dijon, INRAE, University Burgundy Franche-Comté, Dijon, France, ${ }^{6}$ Department of Biology, University of York, York, United Kingdom, ${ }^{7}$ Institut Sophia Agrobiotech, INRAE,
\end{abstract} \\ CNRS, Côte d'Azur University, Sophia-Antipolis, France
}

Legumes of the Fabeae tribe form nitrogen-fixing root nodules resulting from symbiotic interaction with the soil bacteria Rhizobium leguminosarum symbiovar viciae $(R / v)$. These bacteria are all potential symbionts of the Fabeae hosts but display variable partner choice when co-inoculated in mixture. Because partner choice and symbiotic nitrogen fixation mostly behave as genetically independent traits, the efficiency of symbiosis is often suboptimal when Fabeae legumes are exposed to natural $R / V$ populations present in soil. A core collection of $32 R / V$ bacteria was constituted based on the genomic comparison of a collection of 121 genome sequences, representative of known worldwide diversity of $R / v$. A variable part of the nodD gene sequence was used as a DNA barcode to discriminate and quantify each of the 32 bacteria in mixture. This core collection was co-inoculated on a panel of nine genetically diverse Pisum sativum, Vicia faba, and Lens culinaris genotypes. We estimated the relative Early Partner Choice (EPC) of the bacteria with the Fabeae hosts by DNA metabarcoding on the nodulated root systems. Comparative genomic analyses within the bacterial core collection identified molecular markers associated with host-dependent symbiotic partner choice. The results revealed emergent properties of rhizobial populations. They pave the way to identify genes related to important symbiotic traits operating at this level.

Keywords: Rhizobium leguminosarum symbiovar viciae, competitiveness, pea, fababean, lentil, Fabeae, DNA metabarcoding, symbiosis

\section{INTRODUCTION}

Legumes can escape nitrogen-deficit conditions by interacting with rhizobia to form nitrogen-fixing root nodules. In these symbiotic organs, the plant accommodates high densities of differentiated bacteroids able to fix atmospheric $\mathrm{N}_{2}$ into ammonium to fuel plant nitrogen metabolism. Natural populations of rhizobia are often genetically diverse (Young, 1985; Young et al., 2021). Bacteria 
sharing equivalent host-specificity are gathered into symbiovars (sv; Rogel et al., 2011). Genetic diversity based on genomic variation and host specificity are not completely correlated, and sv may include bacteria of multiple species sharing common symbiotic abilities. Rhizobium leguminosarum sv viciae (Rlv) is the specific symbiont of the Fabeae tribe including important crops such as pea (Pisum sativum L.), fababean (Vicia faba L.), and lentil (Lens culinaris L.). The sv viciae bacteria generally belong to the Rhizobium leguminosarum species complex $(R l c)$ that includes other svs, namely trifolii and phaseoli. Rlc bacteria generally have 4-10 plasmids, one of which carries the main nodulation genes (nod) required for symbiosis. Our knowledge of $R l c$ genomic diversity has recently been improved by the release of diverse genome sequences in GenBank (Boivin et al., 2020; Cavassim et al., 2020). Rlc is composed of at least 18 different genospecies which are not symbiovar-specific, as bacteria belonging to the same genospecies may display different host-specificities and symbiotic capacities (Kumar et al., 2015; Boivin et al., 2020; Cavassim et al., 2020; Young et al., 2021).

The host specificity of symbiosis is generally the result of Early Partner Choice (Younginger and Friesen, 2019; Walker et al., 2020). EPC is associated with the diversity of the horizontally transferred symbiosis-related regions of the genome, present on specific plasmids or islands (Young, 2016). These regions include the nod genes involved in the synthesis and secretion of lipo-chito-oligosaccharide Nod Factors (NFs) recognized by the plant. The nodD gene sequence encoding the transcriptional regulator of the bacterial symbiosis genes, activated in response to plant flavonoids, has been successfully used as a marker to discriminate $R l$ symbiovars (Zézé et al., 2001; Laguerre et al., 2003; Boivin et al., 2020). EPC is usually estimated by the Ability of a bacterium to Form root Nodules with a specific legume host (AFN). However, AFN is not sufficient to predict EPC in natural conditions, when multiple compatible partners interact with the same host. Although most of the Rlv bacteria have the capacity to form root nodules with most of the Fabeae legumes, competition occurs between bacteria when they are in populations. Only strains with the highest Competitiveness to Form root Nodules (CFN) finally dominate the symbiotic root system (Ji et al., 2017; Irisarri et al., 2019; Boivin and Lepetit, 2020; MendozaSuárez et al., 2020). Therefore, the proportion of the different genotypes in $R l v$ populations associated with Fabeae root nodules do not necessarily reflect the diversity present in soil. Rlv CFN varies greatly depending upon the legume host and the nod alleles of the bacterial symbiont (Boivin et al., 2020). Moreover, a poor association was often found between CFN and the level of Symbiotic $\mathrm{N}_{2}$ Fixation (SNF; Bourion et al., 2017; Boivin and Lepetit, 2020), explaining the frequent failure of inoculation strategies with strains chosen based on high SNF. There is frequently a higher competitiveness of indigenous ineffective bacteria as compared to inoculated strains (Fesenko et al., 1995; Laguerre et al., 2003; McKenzie et al., 2011). AFN and CFN are not the only mechanisms responsible for EPC between symbiotic partners. When the young nodule becomes $\mathrm{N}_{2}$-fixing, postinfection mechanisms (Laguerre et al., 2012; Wang et al., 2017) may also modulate the development of the nodules occupied by different bacteria, the differentiation of bacteria in bacteroids, as well as the number of viable bacteria. These mechanisms may result in the "sanction" of inefficient bacteria or may induce the senescence of symbiotic organs (for review, see Boivin and Lepetit, 2020). As symbiotic efficiency of bacteria varies according to its host, it is expected that sanction may depend not only on the microsymbiont but also probably of the plant partner (Regus et al., 2017; Westhoek et al., 2021).

Major mechanisms involved in Rhizobium-legume interaction and nodule formation have been elucidated (Oldroyd et al., 2011; Wang et al., 2018). However, very little is known about mechanisms responsible for variation of EPC and CFN. Antibiosis and quorum-sensing mechanisms modulating the multiplication of free-living rhizobia have been reported, and are potentially involved in EPC (Robleto et al., 1997; McAnulla et al., 2007; Naamala et al., 2016). However, even if the preferential proliferation of particular rhizobia within host rhizospheres may contribute to EPC, plant-microbe interactions probably have a major role in EPC (Moawad et al., 1984; Laguerre et al., 2003; Boivin and Lepetit, 2020). Using co-inoculation strategies with high densities of $R l v$ in mixtures, we previously showed that pea and fababean preferentially select some Rlv genotypes, although these bacteria have an equivalent capacity to nodulate all partners (Boivin et al., 2020). Some candidate genes and/or genetic markers associated with pea/fababean CFN were identified. Most of these genomic sequences were on plasmids, in agreement with the hypothesis that some horizontally transferred components control CFN. However, the underlying mechanism(s) remain elusive. Candidate genes included nodulation genes (nod genes) such as $\operatorname{nod} M, \operatorname{nod} N$, nodT, and nodO. These genes were previously identified as highly polymorphic (Jorrin and Imperial, 2015). They were suspected to contribute to host specificity (Djordjevic et al., 1985; Surin and Downie, 1988; Lewis-Henderson and Djordjevic, 1991; Baev et al., 1992). Rhizobia produce a large diversity of NFs that bind to legume root LysM-RLK receptors (Oldroyd et al., 2011; Wang et al., 2018). NFs are composed of a chitin-like $\mathrm{N}$-acetyl glucosamine backbone with a fatty acyl chain at the non-reducing end, and carry various substitutions such as glycosylation, acetylation, and/or sulfation on the backbone (Mergaert et al., 1997). NF modifications may influence the binding between NFs and LysM-RLKs and therefore modulate the establishment of the symbiosis and are likely to affect EPC (Dénarié et al., 1992). In agreement with this hypothesis, the nodX gene has been reported as involved in a mechanism restricting the AFN and resulting in a specific EPC between $R l v$ bacteria that have nodX, such as the strain TOM, and the Pisum sativum cultivar "Afghanistan" (Davis et al., 1988). The nodX gene encodes an acetyltransferase that modifies NF synthesized by TOM allowing a specific interaction with the LysM-RLK protein encoded within the SYM2 locus of the "Afghanistan" cultivar (Firmin et al., 1993; Hogg et al., 2002; Sulima et al., 2017). More broadly, the genetic association of nod gene diversity with bacterial EPC argues for the hypothesis of an important role of NF in the underlying mechanisms (Boivin et al., 2020). However, other mechanisms, related to plant recognition of bacterial surface polysaccharides or bacterial effectors, have been implicated in the modulation of the legume-Rhizobium interaction, and therefore 
may contribute to EPC (Janczarek et al., 2015; Kawaharada et al., 2015; Miwa and Okazaki, 2017).

In most reported co-inoculation experimental strategies able to reveal CFN variation, bacteria were inoculated with a reference strain or with a limited number of strains (Triplett and Sadowsky, 1992; Laguerre et al., 2003; Bourion et al., 2017). Recently, a co-inoculation strategy with multiple Ensifer meliloti strains was applied on two Medicago truncatula genotypes illustrating the important impact of the partner choice diversity on several symbiotic traits (Burghardt et al., 2018). However, the phenotyping was done 5 weeks post-inoculation which did not allow to characterize precisely EPC, because postinfection mechanisms likely already modulate EPC. More recently, Mendoza-Suárez et al. (2020), developed a system of DNA tag and reporter genes on plasmids enabling to monitor both competitiveness and N2 fixation in pea inoculated with multiple $R l v$ strains. In this study, taking the new opportunities offered by both NGS and DNA metabarcoding, we designed a strategy to (1) characterize EPC in Fabeae roots inoculated with an artificial $R l v$ population, and (2) identify $R l v$ genes potentially associated with contrasted EPC phenotypes. We defined a core collection representative of the genomic diversity of the $R l v$. We inoculated this core collection in mixture on three genotypes of each of three Fabeae host species (Pisum sativum, Vicia faba, and Lens culinaris). We used saturating amounts of bacteria to focus on plant-microbe interactions and to reduce impacts of differential bacterial growth. We selected a DNA barcode located on the nodD gene to discriminate and quantify individually each Rhizobium of the core collection within a nodulated root system using high-throughput NGS. We characterized host-specific EPC profiles of the bacteria forming the core collection. Using a comparative genomic approach between bacterial genomes, we identified $R l v$ genes associated with variation of bacterial EPC in the various plant hosts.

\section{MATERIALS AND METHODS}

\section{Bacterial Collection, Inoculation and Plant Growth Conditions}

Rhizobia isolated from Pisum sativum, Vicia faba, Lens culinaris, or Lathyrus pratensis root nodules, and from various geographical origins, were collected (Supplementary Table 1). The Pisum sativum cultivars were "Kayanne"1, "Isard"2 and "Afghanistan" JI13573. The Lens culinaris cultivars were "Rosana," "Anicia," and "Flora" (see text footnote 2). The Vicia faba cultivars were "Diva," "Organdi," (see text footnote 2) and "Tiffany". Plant seeds were surface sterilized in 3\% calcium-hypochlorite solution for $10 \mathrm{~min}$, washed five times in sterilized water, and sown in $2 \mathrm{~L}$ pots filled with sterilized perlite/sand (3/1). We inoculated the seeds with the complex inoculum directly after sowing. Bacterial strains were grown individually in YEM broth medium, the number of

\footnotetext{
${ }^{1}$ www.kws.com

${ }^{2}$ www.agriobtentions.fr

${ }^{3}$ https://www.seedstor.ac.uk/

${ }^{4}$ www.ragt-semences.fr
}

Colony Forming Units (CFU) was estimated by dilution plating and the identity of each bacterium was systematically checked by PCR amplification and sequencing of the nodD gene. Inoculum mixture was obtained by mixing together equal amounts of each bacterium $\left(10^{7} \mathrm{CFU} / \mathrm{mL} / \mathrm{strain}\right)$. For each condition, four pots containing four seeds each were used. Plants were grown under high-pressure sodium lamps with a mean photosynthetically active radiation of $250 \mu \mathrm{mol}$ photons $\mathrm{m}^{-2} \cdot \mathrm{s}^{-1}\left(16 / 8 \mathrm{~h} 22 / 18^{\circ} \mathrm{C}\right.$ day/night cycle). Plants were irrigated twice a week with $\mathrm{N}$-free HY nutrient solution $\left(\mathrm{KH}_{2} \mathrm{PO}_{4} 1 \mathrm{mM}, \mathrm{MgSO}_{4} 1 \mathrm{mM}, 0.25 \mathrm{mM}\right.$ $\mathrm{CaCl}_{2}, 0.25 \mathrm{mM} \mathrm{K}_{2} \mathrm{SO}_{4}, 50 \mu \mathrm{M} \mathrm{KCl}, 30 \mu \mathrm{M} \mathrm{H}_{3} \mathrm{BO}_{3}, 5 \mu \mathrm{M}$ $\mathrm{MnSO}_{4}, 1 \mu \mathrm{M} \mathrm{ZnSO}, 1 \mu \mathrm{M} \mathrm{CuSO}_{4}, 0.7 \mu \mathrm{M}\left(\mathrm{NH}_{4}\right)_{6} \mathrm{Mo}_{7} \mathrm{O}_{24}$, $100 \mu \mathrm{M}$ Na-Fe-EDTA adjusted to $\mathrm{pH}$ 6.5). Plants were harvested 14 days after inoculation for Pisum sativum and Lens culinaris, and 21 days after inoculation for Vicia faba. Roots were rinsed for $2 \mathrm{~min}$ in $\mathrm{CaSO}_{4}$ 0,2 mM.

\section{DNA Extraction, PCR Amplification and Metabarcoding Analysis}

We evaluated the proportion of each strain in the symbiotic root nodules by the nod309 DNA metabarcoding strategy. The nodulated root systems of the four plants of each pot were pooled together to form a DNA metabarcoding biological replicate (four biological replicates per condition were generated). We extracted the DNA from whole nodulated root systems ground in liquid $\mathrm{N}_{2}$ using the DNeasy Plant Mini Kit ${ }^{5}$. PCR amplifications of the nodD309 barcode sequences were performed using Phusion High-Fidelity DNA Polymerase ${ }^{6}$, specific nodD309 MiSeq primers, and conditions (Supplementary Table 2). We systematically checked the size of the amplicons on agarose gels. Amplicons were sequenced by the Genotoul GeT-PlaGe facility $^{7}$ on an Illumina MiSeq platform using a $2 \times 250 \mathrm{bp}$ paired end protocol. Multiplexing was performed using a homemade $6 \mathrm{bp}$ index, which was added to the amplicons during a second PCR with 12 cycles using Miseq_round2 specific primers (Supplementary Table 2). Purified PCR products were loaded onto the Illumina MiSeq cartridge according to the manufacturer's instructions. Paired Illumina MiSeq reads were assembled with vsearch v2.9.1 (Rognes et al., 2016) using the command fastq_mergepairs and the option fastq_allowmergestagger. Demultiplexing and primer clipping were performed with cutadapt v1.9 (Martin, 2011) forcing a fulllength match for sample tags and allowing a 2/3rd-length partial match for forward and reverse primers. Only reads containing both primers were retained. For each trimmed read, the expected error was estimated with vsearch's command fastq_filter and the option eeout. Each sample was then dereplicated (i.e., strictly identical reads were merged) using vsearch's command derep_fulllength, and converted to FASTA format. To prepare for clustering, the samples were pooled and processed with another round of dereplication. Files containing expected error estimates were also dereplicated to retain only the lowest expected error for each unique sequence. To detect potential contaminants,

\footnotetext{
${ }^{5}$ www.qiagen.com

${ }^{6}$ www.thermofisher.com

${ }^{7}$ https://get.genotoul.fr
} 
the dereplicated data were further clustered with swarm v2.1.9 (Mahé et al., 2015), and checked for chimeras using vsearch's command uchime_denovo (Edgar et al., 2011). As no significant contamination was detected, downstream analyses, and results are based on unclustered data, only retaining reads strictly identical to the 32 expected Rhizobium nodD309 reference sequences (Supplementary Table 3), yielding a total of 511294 reads for all replicates. A mean of 14203 reads per condition was generated (Supplementary Table 4). We calculated the Early Partner Choice (EPC) index of a bacterium in a plant host as the percentage of the nodD309 sequences of the Rhizobium of interest divided into the total number of nodD309 sequences generated by all rhizobia of the sample (Supplementary Table 5). EPC index values are the mean of four biological replicates. Variation in the four biological repeats was estimated by calculating the variation coefficient (CV\%) for each DNA barcode in all combinations (Supplementary Figure 1). A CV value below 50\% was observed for half of the assays indicating an acceptable reliability of the EPC estimate.

\section{NodX Complementation Assays}

To investigate if the nodX sequence polymorphism was responsible for nodulation specificity of pea cV "Afghanistan," 3841 and CCBAU43229, two Nod type B strains lacking nodX, were complemented with the two nodX genes from TOM or from P221 rhizobia on transfected plasmids. The strategy was equivalent to Fliegmann et al. (2016) and SevinPujol et al. (2017). Briefly, a broad-host-range cloning vector pFAJ1700GG adapted to the golden gate cloning methodology (Engler et al., 2009) was constructed by inserting a SnaBIAvrII fragment from pCAMBIA-CR1 (containing a lacZ cassette; Fliegmann et al., 2016), into PmeI-XbaI of the pFAJ1700 cloning vector (Dombrecht et al., 2001). In $R l v$, the nodX gene is the last gene of the nodABCIJX operon (Davis et al., 1988). A 300 bp DNA fragment carrying a nod box located upstream of the Rlv TOM nodA coding sequence was amplified from genomic DNA using primers abpromnodA1 and abpromnodA2 (Supplementary Table 2), and cloned into pJET vector. The nodX coding sequences were PCR amplified from Rlv TOM and Rlv P221 genomic DNA using primers bdnodxtom1 and bdnodxtom2 (Supplementary Table 2) and cloned into pJET and pGEMT vectors, respectively. The nod box containing the promoter and the nodX coding sequence modules were assembled in one step into the pFAJ1700GG vector, by a digestion-ligation reaction in the presence of $B s a \mathrm{I}$ and T4DNA ligase as described in Engler et al. (2009). The resulting plasmids, carrying the two versions of nodX under the control of the same promoter (DH5a Escherichia coli strain), were transferred into the Rlv strains 3841 and CCBAU43229 by triparental mating using pRK2013 (in E. coli K12) as helper strain (Ditta et al., 1980). For nodulation assays, sterilized pea seeds were germinated on $40 / 60 \mathrm{v} / \mathrm{v}$ pouzzolane/charred clay granules (oil dri from Oil Dri United Kingdom, Bannisters Row, Wisbech, Cambridgeshire) substrate supplemented with Fahraeus medium (Catoira et al., 2000). The growth conditions were $20^{\circ} \mathrm{C}$ and a mean photosynthetically active radiation of $65 \mu \mathrm{mol}$ photons $\mathrm{m}^{-2} \cdot \mathrm{s}^{-1}\left(16 / 8 \mathrm{~h} 22 / 18^{\circ} \mathrm{C}\right.$ day/night cycle). Seedlings were mono-inoculated with $5 \mathrm{ml}$ of a fresh culture $\left(\mathrm{OD}_{600 \mathrm{~nm}}=0.5\right)$ of recombinant rhizobial strains or parental ones. Nodules were scored 3 weeks after inoculation.

\section{Genome Sequencing, Genomic and Association Genetic Analysis}

Bacterial genomes were sequenced by MicrobesNG (Birmingham, United Kingdom $)^{8}$ on an Illumina HiSeq platform using a $2 \times 250$ bp paired end protocol. Genomic DNA libraries were prepared using Nextera XT Library Prep Kit (Illumina, San Diego, CA, United States). High-quality paired reads were assembled by the Galaxy/BBRIC pipeline ${ }^{9}$ and genome annotations were performed using EuGene-PP (Sallet et al., 2014), and $\mathrm{RAST}^{10}$. The pairwise ANI values were calculated using the JSpecies software (Supplementary Table 8) ${ }^{11}$. Strains were assigned to genospecies based on ANI and core gene phylogeny (Young et al., 2021). Heatmaps were built using the pheatmap R package (Kolde, 2019). Presence/absence of genes associated with EPC indexes were identified using the Bidirectional Best Hits (BBHs) tool available in RAST (see text footnote 10). The presence/absence of the specific genes identified was checked by a BLAST search in the genomes of the core collection (thresholds: nucleotide identity $>70 \%$; sequence coverage $>70 \%$ ). Kruskal-Wallis tests (eventually followed by a Dunn post hoc test with the "Bonferroni" correction for multiple testing) were performed using $\mathrm{R}$ software ${ }^{12}$ to test whether the bacterial subgroups displayed equivalent EPC indexes $\left(\mathrm{H}_{\mathrm{o}}\right.$ hypothesis), according to diverse criteria (genospecies/Nod types/groups with specific allele). The nucleotide sequences of the nodABCDEFIJLMN genes were concatenated and aligned using ClustalOmega ${ }^{13}$, and a Neighbor-Joining (NJ) phylogenetic tree was built using MEGA v7.0.26 ${ }^{14}$. The comparisons between reference genomes, and between contigs and the genomic sequence of 3841, for genomic rearrangements/organization (Supplementary Tables 6, 7), were performed using MAUVE software (Darling et al., 2004). Plasmid replicon classes (Rh groups) were identified by sequence similarity of the repA gene and presence of cognate repB and repC (Cavassim et al., 2020).

\section{RESULTS}

\section{Constitution of a Bacterial Core Collection of Fabeae Rhizobial Symbionts}

At the beginning of this study, we collected 73 genome sequences of Fabeae symbionts available in GenBank (Supplementary Table 1). To increase the diversity, the genomes of 48

\footnotetext{
${ }^{8}$ https://microbesng.uk/

${ }^{9}$ https://bbric-pipelines.toulouse.inra.fr/

${ }^{10}$ http://rast.nmpdr.org/

${ }^{11} \mathrm{http}: / /$ jspecies.ribohost.com/jspeciesws

${ }^{12} \mathrm{http}: / /$ www.R-project.org/

${ }^{13}$ www.ebi.ac.uk

${ }^{14}$ www.megasoftware.net
} 
additional rhizobia from diverse geographical origins, and/or carrying diverse sequences of the symbiotic marker nodD belonging to the symbiovar (sv) viciae, were also sequenced (Supplementary Table 1). All rhizobia have been isolated in previous studies from Fabeae root nodules (Pisum sativum, Vicia faba, Lens culinaris, and Lathyrus pratensis). Most of the bacteria (117/121) shared an Average Nucleotide Identity (ANI) $>92 \%$ (Figure 1 and Supplementary Table 8). They belonged to nine of the $R$. leguminosarum complex $(R l c)$ genospecies previously described: gsB, gsC, gsD, gsE, gsG, gsN, gSO, gsQ, and gsR (Young et al., 2021). Four other strains were phylogenetically distant from the others $(88 \%<$ ANI $<90 \%$; Supplementary Table 8) and hence outside the $R l c$, but included inside the $R$. leguminosarum-etli clade according the recent study of Young et al. (2021).

The 121 bacteria of the collection were also discriminated according to their plasmid-borne symbiosis genes. A phylogenetic tree was constructed using the sequence of the 11 conserved nod genes located on the symbiosis plasmid (Figure 2). Based on the nod gene phylogeny, the Rlv bacteria were separated into the two Nod types, named A and B previously described in Boivin et al. (2020). These phylogenetic groups gather strains sharing closely related nod genes sequences and displaying contrasted preferential host specific competitiveness with pea or fababean, respectively (Boivin et al., 2020). Based on the nod genes sequences, these two Nod types were further subdivided into 10 Nod groups named A1-A5 and B1-B5, respectively. In each Nod group, bacteria display nod sequence variation, except for the 22 strains of the B1 group that only had very few differences. A total of $44 \mathrm{gs} / \mathrm{Nod}$ group combinations were identified within the 121 bacteria, confirming a diversity of association between the symbiosis plasmid and the genospecies (Supplementary Table 6). The number of bacteria per combination is variable. For instance, 19 strains carried the combination gsE/A1 whereas only one strain had gsB/A2 (Supplementary Table 6). The presence of the nodX gene within the nod gene cluster was surprisingly not restricted to the TOM strain, but was present in 27/121 isolates, including both A and B types (Figure 2).

In order to identify and quantitate individual rhizobial strains in the root system after inoculation with a mixture of many strains, we designed a DNA metabarcoding strategy to evaluate

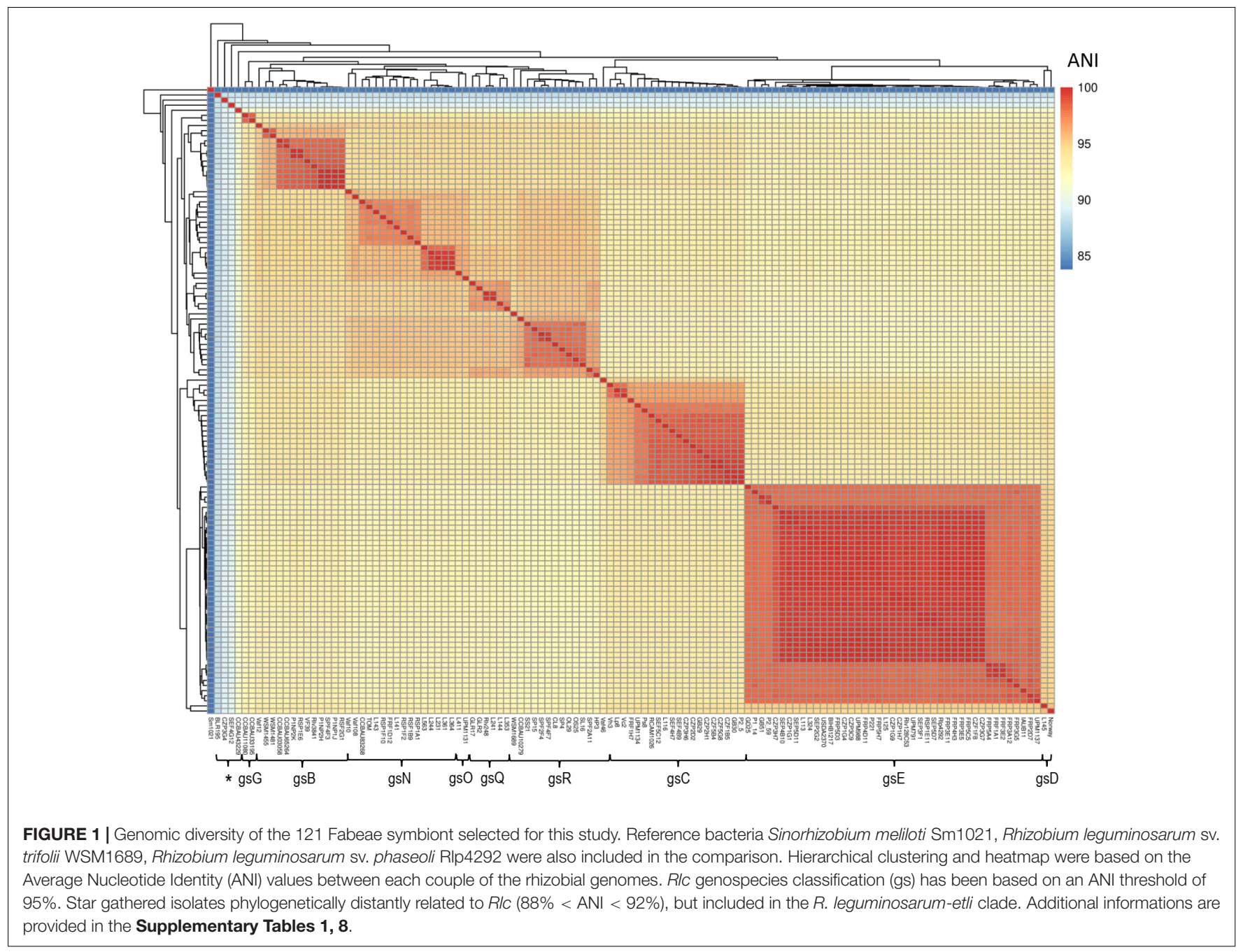




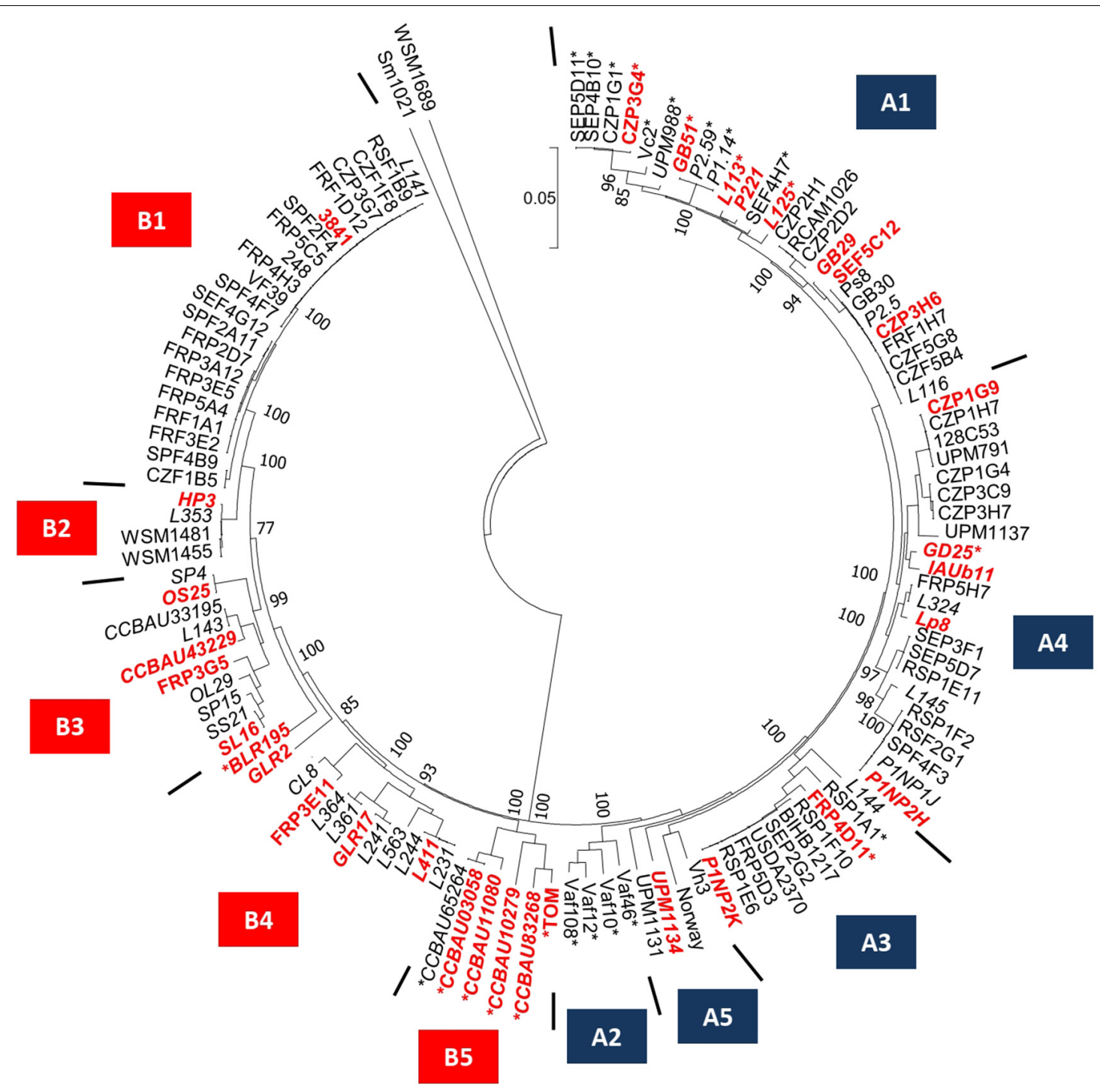

FIGURE 2 | Nod gene cluster diversity of the 121 Fabeae symbiont genomes selected for this study. Phylogenetic tree was based on the nodABCDEFIJLMN concatenated gene sequences of the 121 R/v genomes. Red and blue boxes defined Nod groups. The 48 new Fabeae symbiont genomes are indicated in italic. The 32 rhizobia of the core collection are indicated in red. Stars indicate rhizobia carrying the nodX gene within the nod gene cluster. Rhizobium leguminosarum symbiovar trifolii WSM1689 and Sinorhizobium meliloti 1021 have been used as outgroups.

the proportion of each strain in the symbiotic root nodules. We sought a gene that was diverse enough in sequence to act as a natural barcode. The $16 \mathrm{~S}$ or gyrB marker sequences, frequently used in DNA metabarcoding strategies, did not display sufficient intraspecific genetic variation among the 121 strains. Furthermore, they belonged to the chromosome and therefore were poorly genetically linked to most symbiotic phenotypes. The nodD gene sequence variations has been already used to discriminate $R l$ bacteria, particularly between and within symbiovars (Zézé et al., 2001; Laguerre et al., 2003; Mutch and Young, 2004; Boivin et al., 2020; Young et al., 2021). We therefore designed a barcode containing a $309 \mathrm{bp}$ fragment of the nodD gene, located on the symbiosis plasmid. This sequence displayed 32 nodD unique alleles among the 121 strains (Supplementary
Table 3). These 32 alleles were distributed among the 10 Nod groups and each Nod group had at least one specific allele (Supplementary Table 6). Based on this barcode, 32 bacteria were finally selected to constitute a Fabeae symbiont core collection, representative of the geographical origins, the plant hosts used for isolation, the diversity of gs/Nod group combinations, and the presence/absence of nodX (Table 1, Supplementary Figure 2, and Supplementary Tables 3, 6). Indeed, most geographical origins (87\%), all plant hosts used for trapping (100\%), and most of the gs/Nod group combinations (67\%), were represented in this core collection, which included numerous bacteria with nodX $(12 / 32)$. Nevertheless, it is noteworthy that, because of the limited variation of the barcode, we could introduce only one strain representing the abundant B1 Nod group. 
TABLE 1 | Rhizobium leguminosarum symbiovar viciae bacteria included in the core collection.

\begin{tabular}{|c|c|c|c|c|}
\hline Strains & Isolated from & Locations & Genospecies & Nod groups \\
\hline 3841 & Vicia faba & United Kingdom & $g s B$ & B1 \\
\hline BLR195 & Lens culinaris & Bangladesh & $\begin{array}{c}\text { Rhizobium } \\
\text { binae }\end{array}$ & $\mathrm{B} 4+$ \\
\hline CCBAU03058 & Vicia faba & China & gsB & $\mathrm{B} 5+$ \\
\hline CCBAU10279 & Vicia faba & China & gsR & $\mathrm{B} 5+$ \\
\hline CCBAU11080 & Vicia faba & China & gsG & $\mathrm{B} 5+$ \\
\hline CCBAU43229 & Vicia faba & China & $\begin{array}{l}\text { Rhizobium } \\
\text { anhuiense }\end{array}$ & B3 \\
\hline CCBAU83268 & Vicia faba & China & gsN & $\mathrm{B} 5+$ \\
\hline CZP1G9 & Pisum sativum & Czech Republic & gsE & A4 \\
\hline CZP3G4 & Pisum sativum & Czech Republic & $\begin{array}{c}\text { Rhizobium } \\
\text { pisi }\end{array}$ & $\mathrm{A} 1+$ \\
\hline CZP3H6 & Pisum sativum & Czech Republic & gsC & A1 \\
\hline FRP3E11 & Pisum sativum & France & gsE & B4 \\
\hline FRP3G5 & Pisum sativum & France & gsE & B3 \\
\hline FRP4D11 & Pisum sativum & France & gsE & $\mathrm{A} 3+$ \\
\hline GB29 & Pisum sativum & Poland & $\mathrm{gsC}$ & $\mathrm{A} 1$ \\
\hline GB51 & Pisum sativum & Poland & gsE & $\mathrm{A} 1+$ \\
\hline GD25 & Pisum sativum & Poland & gsE & $\mathrm{A} 4+$ \\
\hline GLR17 & Lens culinaris & Germany & $g s Q$ & B4 \\
\hline GLR2 & Lens culinaris & Germany & gsQ & B4 \\
\hline HP3 & Pisum sativum & Algeria & gsR & B2 \\
\hline IAUb11 & Pisum sativum & France & gsE & A4 \\
\hline L113 & Lens culinaris & France & gsE & $\mathrm{A} 1+$ \\
\hline L125 & Lens culinaris & France & gsE & $\mathrm{A} 1+$ \\
\hline$\llcorner 411$ & Lens culinaris & France & $\mathrm{gsO}$ & B4 \\
\hline Lp8 & $\begin{array}{l}\text { Lathyrus } \\
\text { pratensis }\end{array}$ & United Kingdom & $\mathrm{gsC}$ & A4 \\
\hline OS25 & Pisum sativum & Algeria & gsR & B3 \\
\hline $\mathrm{P} 1 \mathrm{NP} 2 \mathrm{H}$ & Pisum sativum & France & gsB & A4 \\
\hline P1NP2K & Pisum sativum & France & gsB & A3 \\
\hline P221 & Pisum sativum & France & gsE & $\mathrm{A} 1+$ \\
\hline SEF5C12 & Vicia faba & Sweden & $\mathrm{gsC}$ & A1 \\
\hline SL16 & Lens culinaris & Algeria & gsR & B3 \\
\hline TOM & Pisum sativum & Turkey & gsN & $\mathrm{B} 5+$ \\
\hline UPM1134 & Pisum sativum & Italy & $\mathrm{gsC}$ & A5 \\
\hline
\end{tabular}

${ }^{\dagger}$ Bacteria carrying the nodX gene within the nod gene cluster.

\section{Early Partner Choice Varies Across Fabeae Host Plants}

The $32 R l v$ bacteria of the core collection constituted the inoculum mixture. We combined saturating densities of each of the 32 bacteria $\left(10^{7} \mathrm{CFU} / \mathrm{mL}\right.$ for each strain) to minimize the putative impact of bacterial growth on nodulation success. We inoculated three genotypes of each of the host plant species Pisum sativum, Lens culinaris, and Vicia faba, covering a large genetic diversity of these legume crops, with the Rlv core collection. Root systems were harvested once nodules were emerged just starting to be fixating (14 days after inoculation; small and white nodules), and the nodD309 DNA barcode was PCR-amplified from the total DNA extractions. The sequencing of the PCR product yielded numbers of nodD309 sequences, specific to each member of the core collection present in the nodulated root system. Among the
32 bacteria, six were removed from the further analyses as no read was detected in any sample from any host (Supplementary Tables 4, 5). Although the TOM DNA barcode was rare in roots systems of all hosts, few reads were detected and therefore it was included in the analysis. We calculated the Early Partner Choice (EPC) index for each strain in each host plant. The EPC index of the 26 bacteria detected in metabarcoding ranged from 0 to $81.9 \%$ (Supplementary Table 5). The mean EPC per bacterium in all hosts ranged from 0.003 to $32.2 \%$. A hierarchical clustering based on the EPC indexes of the 26 bacteria of the core collection detected in metabarcoding separated plant hosts into four groups displaying distinct competitiveness profiles (Figure 3). These four groups were composed, respectively, of the Vicia faba genotypes, the Lens culinaris genotypes, the Pisum sativum cultivars "Kayanne" and "Isard" (cultivated spring and winter peas), and the Pisum sativum cultivar "Afghanistan." For the bacteria the clustering was less marked than for plants (Figure 3 and Supplementary Table 7).

\section{NodX Is Required but Not Sufficient for Nodulation of Pisum sativum cv "Afghanistan"}

The Pisum sativum cultivar "Afghanistan" (carrying the SYM2 allele) is described in the literature to associate specifically with some $R l v$ strains having the nodX gene (such as the TOM strain that has been frequently used). It is therefore a good case study to validate our metabarcoding strategy. The nodulation profile of this plant genotype was indeed highly divergent compared to the other pea cultivars (Figure 3). Our data confirmed that the bacterial nodX gene is required for EPC with this plant genotype, as $89 \%$ of the reads detected in nodulated roots of this plant genotype belong to BLR195, CCBAU11080, and CCBAU10279. These three bacteria were not found in such high amounts with other pea cultivars. Nevertheless, neither the presence of nodX, nor the Nod type, nor the genospecies, were alone significantly associated with nodulation success on this host (Supplementary Tables 8, 9). In addition to BLR195, CCBAU11080, and CCBAU10279, eight other bacteria of the core collection, belonging to the Nod types A or B, also had the nodX gene. However, they did not display a systemically preferential EPC with cv "Afghanistan" (Table 1 and Supplementary Table 9). Only strains having the nodX gene and belonging to Nod type B may display high EPC, suggesting that both criteria are required simultaneously for nodulation of pea $c v$ "Afghanistan" (Supplementary Table 9). However, this criteria is probably not sufficient as some Nod type B bacteria carrying nodX may display poor EPC with pea $c v$ "Afghanistan." Monoinoculation experiments with strains carrying nodX confirmed that strains with Nod type B were able to form nodules with the pea cv "Afghanistan," even TOM or CCBAU83868 that showed a poor EPC when inoculated in mixture, whereas the strains with Nod type A were unable, even though they carried nodX (Supplementary Table 10). To investigate if the nodX sequence polymorphism was responsible for this nodulation specificity, 3841 and CCBAU43229, two Nod type B strains lacking nodX, were complemented with the nodX gene either from TOM (Type 


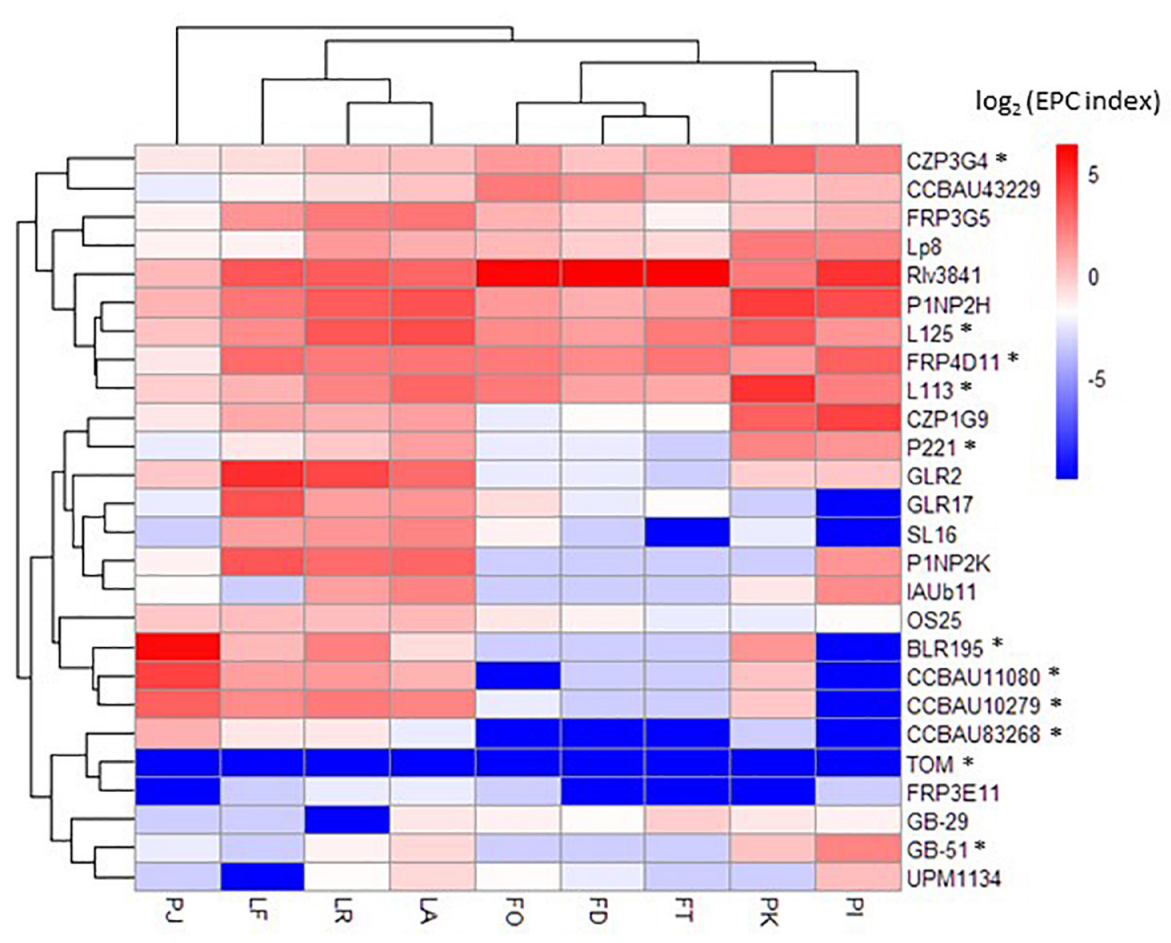

FIGURE 3 | Early partner choice of RIV bacteria with Fabeae plant species/genotypes. Hierarchical clustering and heatmap are based on the EPC indexes for each condition. Only the 20 rhizobia with the best EPC indexes within the core collection are included. Stars indicate the rhizobia carrying the nodX gene within the nod gene cluster. FO, Vicia faba cultivar "Organdi"; FD, Vicia faba cultivar "Diva"; FT, Vicia faba cultivar "Tiffany"; PK, Pisum sativum cultivar "Kayanne"; PI, Pisum sativum cultivar "Isard"; PJ, Pisum sativum cultivar "Afghanistan J11357"; LF, Lens culinaris cultivar "Flora"; LR, Lens culinaris cultivar "Rosana"; LA, Lens culinaris cultivar "Anicia."

B) or from P221 (type A) rhizobia. All the transformants were able to nodulate the pea cv "Afghanistan" as much as the TOM strain, used as positive control (Figure 4). We concluded that the sequence differences in the NodX protein between the type A and type B strains were not responsible for the inability of the Nod type A strains to form nodules with the pea cv "Afghanistan." We concluded that factors independent of NodX, present in the Nod type B but absent in Nod type A strains, are necessary for the nodulation specificity with the pea cv "Afghanistan." Additionally, type B strains carrying nodX, able to form nodules with the pea cv "Afghanistan," may display different levels of competitiveness to form nodule when inoculated in mixture.

\section{Host-Specific EPC Factors Are Associated With Nod Type and/or Genospecies}

Beyond the particular case of pea cultivar "Afghanistan," the various Fabeae genotypes form nodules with all the 26 bacteria from the core collection. However, the three other groups of pea, lentil, and fababean cultivars displayed contrasted EPC profiles when inoculated with these bacteria in mixture not reflecting the initial proportion of the complex inoculum (Figure 3). Therefore, this revealed host-specific EPC of the various bacteria. Strain 3841 was particularly predominant in the three Vicia faba genotypes (from 70 to $82 \%$ of the total reads in the fababean roots) but not in other Fabeae genotypes. This result provided a further validation of the metabarcoding strategy, as 3841 belong to the nod type B1 that was shown to gather strains highly competitive with fababean (Boivin et al., 2020). Unfortunately, as 3841 is the only strain of the core collection belonging to the Nod group B1, it was not possible to extend the comparison to other B1 strains in order, potentially, to associate genetic variation with fababean EPC. However, many strains of the core collection displayed a wide range of EPC variation with the pea and lentil hosts, allowing further investigations. In these cases, it was possible to address the question of the association of these traits with particular genome variants. Strain GLR2 was found at high levels in nodulated roots of the three Lens culinaris genotypes, but not in other Fabeae species (Figure 3). In a smaller proportion, contrasted EPC profiles were also observed between plant genotypes of each plant species. For example, strains 3841 and L113 were differentially competitive with the pea cultivars "Kayanne" and "Isard" (Figure 3).

We investigated associations with the Nod type, the Nod group, or the genospecies of the bacteria, at two levels of plant diversity in lentil and pea: the plant cultivar/genotype (Table 2) and the plant species (Table 3). Because of the limited number of strains of the core collection belonging in each category (Nod type, Nod group, and genospecies) and the limited number of plant genotypes, the power of the statistical analysis was limited especially at the cultivar level. Nevertheless, the Nod 


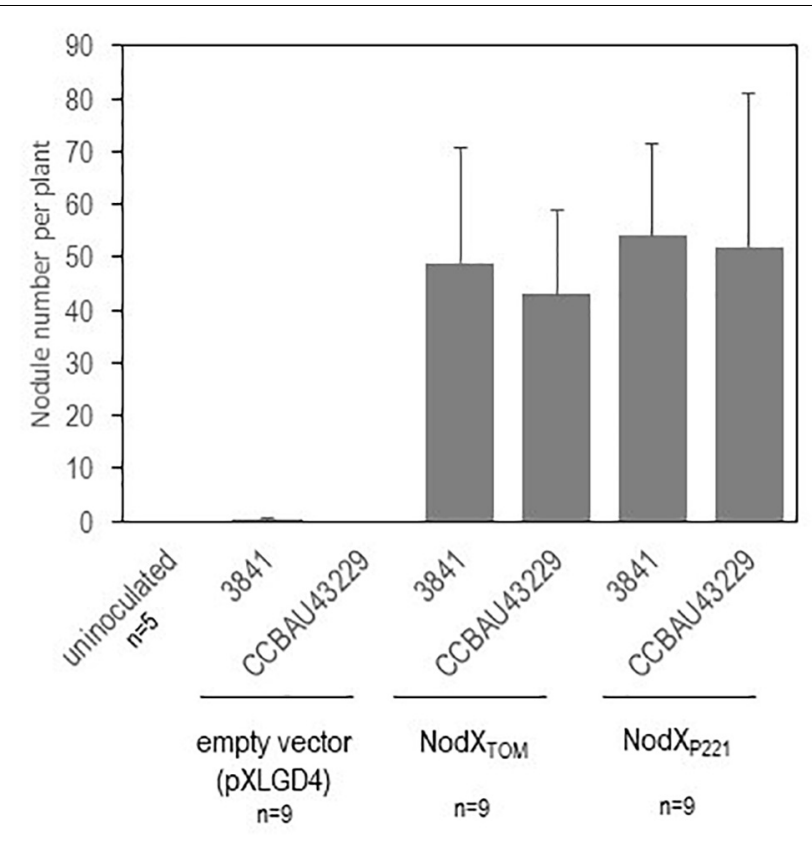

FIGURE 4 | Complementation of Nod type B R/v strains with plasmid constructs expressing NodX. Sterile plantlets of Pisum sativum cv. "Afghanistan" were mono-inoculated with various R/v bacteria. 3841 and CCBAU43229 were transformed with empty vector and were compared with the same rhizobial strain expressing NodX from TOM or P221. Nodule number per plant $(n=9)$ were scored 3 weeks after inoculation. Values are mean \pm SD.

type was associated with the EPC phenotype in the two pea cultivars "Isard" and "Kayanne," but not in lentil (Table 2). We identified association with the Nod group with pea cultivard "Isard." The genospecies was significantly associated with the EPC phenotype in the Pisum sativum cultivar "Isard" as well as in lentil cultivars "Anicia" and "Flora." Investigations at the level of the plant species were obtained by combining the data obtained on the various cultivars (Table 3). Strains with Nod type A generally displayed higher EPC in Pisum sativum. Strains of the core collection belonging to the Nod groups A1 and A4 had a higher mean EPC than those belonging to Nod groups B3, B4, and B5 (Table 3). The only exception is 3841, the unique representative of the $\mathrm{B} 1$ Nod group of the core collection, which displayed high EPC with pea. This particular result was somehow in contradiction with our previous observations indicating that natural isolates from this Nod group are good competitor with fababean, but not with pea (Boivin et al., 2020). Although EPC indexes of strains belonging to various Nod groups varied widely in lentil, we got no evidence indicating that the Nod type or the Nod group could predict EPC with this plant host. We found associations between genospecies and rhizobial EPC in pea (particularly in the "Isard" cultivar) and in lentil. Some of them are common to both host species. For instance, strains belonging to gsB often displayed high EPC indexes in pea and lentil whereas gsN strains always performed poorly with these hosts. Nevertheless, there were also host-specific examples. For example, strains belonging to gsR were in the medium range of
EPC indexes in lentil but in the low range in pea. Despite these global trends, associations were never systematic and exceptions may be observed.

\section{Contrasted EPC Profiles Associate With the Presence of Specific Genes}

Comparative genomics analyses identified rhizobial genetic factors associated with the contrasted nodulation profiles. For each plant genotype, we compared the 4-5 bacterial strains with the highest EPC indexes against the 4-5 with the lowest EPC indexes to identify genes specifically present or absent within their genomes. Then, we tested, in the whole set of 26 bacteria that were detected in the root systems, if the presence/absence of the identified genes was significantly associated with the EPC (Supplementary Table 9). Using this strategy, the number of specific genes identified varied from 2 to 13 depending on the plant species and the cultivar. In the particular case of the Pisum sativum cv "Afghanistan," only a fraction the strains of the core collection were able to form nodules with this host. Our first aim was to identify the genetic factors that, together with nodX, allow this host-specific nodulation. We restricted the first genomic comparison to the eight bacteria of the core collection carrying the nodX gene and belonging either to Nod type A (five strains unable to nodulate this host) or Nod type B (three strains able to nodulate this host). Seventeen genes (named PAFN) associated with ability to form nodule with cv "Afghanistan" were identified by this comparison (Table 4 and Supplementary Table 11). Our second aim was to identify genetic factors specifically associated with competitiveness to form nodule with cv "Afghanistan" by comparing bacteria able to form nodules with this host (i.e., the five Nod type B strains containing the nodX gene) but displaying contrasted EPC when inoculated in mixture. The genomic comparisons identified six additional genes (named PA; Table 4 and Supplementary Table 9). We applied a similar strategy for genome comparisons of strains that displayed contrasted EPC in association with pea and lentil (Table 4 and Supplementary Table 9). This analysis yielded a total of 36 candidate genes potentially involved in the EPC of the core collection with pea cultivars "Isard" and "Kayanne" (named PI and PK, respectively) and lentil cultivars "Anicia," "Rosana," and "Flora" (named LA, LR, and LF, respectively). Candidate genes involved in many functions such as amino acid transport (L-proline/glycine betaine transporter), amino acid modifications (aminotransferase), nucleic acid repair/modification (DNA/RNA helicase, excinuclease), VapC toxin-antitoxin system, and bacteroid aerotolerance (bat operon), as well as genes with unknown functions were identified (Table 4 and Supplementary Table 14).

Homologs of these genes were sought in the six fully assembled Rlv genomes described in GenBank: not only in the reference strain 3841 but also in Vaf10, Vaf108, BIHB1217, UPM791, and TOM. Because $R l v$ genomes contain multiple plasmids actively rearranged, one issue was to define homologous replicons of the various bacteria. The repABC genes control replication and maintenance of plasmids in Rhizobium. Their sequence specificities allow replicons to be defined on the basis of the 
TABLE 2 | Global effect of the R/V genospecies, Nod types and Nod groups on EPC in particular pea and lentil cultivars inoculated with the R/V core collection.

\begin{tabular}{|c|c|c|c|c|c|c|}
\hline & \multicolumn{3}{|c|}{ Pisum sativum } & \multicolumn{3}{|c|}{ Lens culinaris } \\
\hline & cv. Kayanne & cv. Isard & cv. Afghanistan & cv. Anicia & cv. Rosana & cv. Flora \\
\hline Genospecies & n.s & 0.0322 & n.s & n.s & n.s. & 0.0489 \\
\hline Nod type & 0.0253 & 0.0006 & n.s & n.s & n.s & n.s \\
\hline Nod group & n.s. & 0.0042 & n.s & n.s & n.s & n.s \\
\hline
\end{tabular}

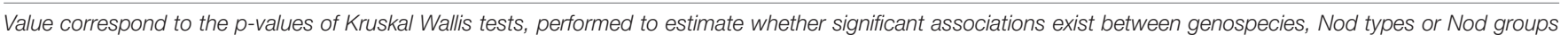

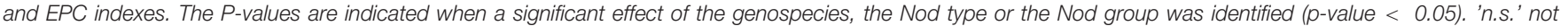
significant.

TABLE 3 | Effect of the plant species on the EPC indexes as a function of the R/v Nod types, Nod groups, or genospecies in pea (cv Kayanne and Isard) and lentil (cV Anicia, Rosana and Flora) associated with the R/v core collection.

\begin{tabular}{|c|c|c|c|c|c|c|c|c|c|}
\hline & & \multicolumn{2}{|r|}{ Pea } & \multicolumn{3}{|r|}{ Lentil } & & \multicolumn{2}{|c|}{ pea and lentil } \\
\hline & & Median & Dunn pairwise test & & Median & Dunn pairwise test & & median & Dunn pairwise test \\
\hline \multicolumn{2}{|c|}{ Nod types } & & & Nod types & & & Nod types & & \\
\hline \multicolumn{2}{|c|}{$p$-value KruskalWallis } & & $1.90 .10^{-5}$ & & & n.s & & & $4.00 .10^{-3}$ \\
\hline$A$ & $n=26$ & 3.95 & $a_{4}$ & $\mathrm{n}=39$ & 1.9 & - & $\mathrm{n}=65$ & 2.9 & $a_{6}$ \\
\hline B & $n=26$ & 0.2 & $b_{4}$ & $\mathrm{n}=39$ & 2.4 & - & $\mathrm{n}=65$ & 1.1 & $b_{6}$ \\
\hline \multicolumn{2}{|c|}{ Nod groups } & & & Nod groups & & & Nod groups & & \\
\hline \multicolumn{2}{|c|}{$\mathrm{p}$-value KruskalWallis } & & $4.60 .10^{-5}$ & & & $2.70 .10^{-3}$ & & & $6.90 .10^{-6}$ \\
\hline A1 & $n=12$ & 3.45 & $a_{1}$ & $\mathrm{n}=18$ & 0.75 & $b_{2}$ & $n=30$ & 1.9 & $b_{3} c_{3}$ \\
\hline A3 & $n=4$ & 2.75 & $a_{1} b_{1}$ & $n=6$ & 7.25 & $a_{2}$ & $n=10$ & 6.5 & $a_{3} b_{3}$ \\
\hline A4 & $n=8$ & 7.15 & $a_{1}$ & $\mathrm{n}=12$ & 2.25 & $a_{2} b_{2}$ & $n=20$ & 3.95 & $a_{3} b_{3}$ \\
\hline A5 & $\mathrm{n}=2$ & 0.65 & $a_{1} b_{1}$ & $n=3$ & 0.3 & $b_{2}$ & $\mathrm{n}=5$ & 0.3 & $c_{3}$ \\
\hline B1 & $n=2$ & 14.45 & $a_{1}$ & $n=3$ & 9.9 & $a_{2}$ & $n=5$ & 9.9 & $a_{3}$ \\
\hline B3 & $n=8$ & 0.6 & $b_{1}$ & $n=12$ & 2.6 & $a_{2} b_{2}$ & $n=20$ & 1.25 & $c_{3} d_{3}$ \\
\hline B4 & $n=8$ & 0.1 & $b_{1}$ & $\mathrm{n}=12$ & 2.65 & $a_{2} b_{2}$ & $n=20$ & 0.85 & $c_{3} d_{3}$ \\
\hline B5 & $n=8$ & 0 & $b_{1}$ & $n=12$ & 0.95 & $b_{2}$ & $n=20$ & 0.35 & $d_{3}$ \\
\hline \multicolumn{2}{|c|}{ Genospecies } & & & Genospecies & & & Genospecies & & \\
\hline \multicolumn{2}{|c|}{$p$-value KruskalWallis } & & $2.50 .10^{-3}$ & & & $1.50 .10^{-6}$ & & & $7.10 .10^{-7}$ \\
\hline gsB & $n=6$ & 9.75 & $a_{7}$ & $n=9$ & 9.6 & $a_{8}$ & $\mathrm{n}=15$ & 9.6 & $a_{9}$ \\
\hline gsC & $n=6$ & 0.85 & $a_{7} b_{7}$ & $n=9$ & 0.4 & $b 8$ & $n=15$ & 0.5 & b9 \\
\hline gsE & $n=18$ & 3.35 & $a_{7} b_{7}$ & $\mathrm{n}=27$ & 2.3 & $a b 8$ & $n=45$ & 2.9 & $a_{9} b 9$ \\
\hline gsG & $n=2$ & 0.55 & $a_{7} b_{7}$ & $n=3$ & 2.3 & $a b_{8}$ & $n=5$ & 1.4 & $a_{9} b 9$ \\
\hline gsN & $n=4$ & 0 & $b 7$ & $n=6$ & 0.1 & b8 & $n=10$ & 0 & $c 9$ \\
\hline$g s Q$ & $n=4$ & 0.45 & $a_{7} b_{7}$ & $\mathrm{n}=6$ & 10.1 & $a_{8}$ & $n=10$ & 2.65 & $a_{9} b 9$ \\
\hline gsR & $n=6$ & 0.2 & $a_{7} b_{7}$ & $n=9$ & 3.2 & $a b_{8}$ & $n=15$ & 1.3 & b9 \\
\hline R. binae & $n=2$ & 1.4 & $a_{7} b_{7}$ & $n=3$ & 1.3 & $a b_{8}$ & $n=5$ & 1.3 & $a_{9} b 9$ \\
\hline R. anhuiense & $n=2$ & 1.1 & $a_{7} b_{7}$ & $n=3$ & 0.6 & b8 & $n=5$ & 0.9 & $a_{9} b 9$ \\
\hline R. pisi & $n=2$ & 6.05 & $a_{7} b_{7}$ & $n=3$ & 1.1 & $a b_{8}$ & $\mathrm{n}=5$ & 1.2 & $a_{9} b 9$ \\
\hline
\end{tabular}

Kruskal Wallis tests were performed to estimate whether bacterial categories were equivalent (Ho hypothesis). P-value are indicated when significant effects of the

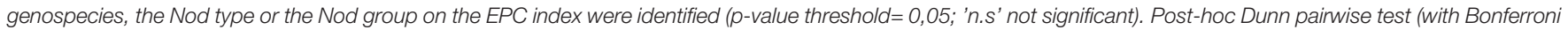
correction for multiple testing) were performed to identify bacterial categories displaying relative differences as indicated by italic letters $\left(a_{i}, b_{i}, c_{i}, d_{i}\right)$.

"Rh" putative incompatibility groups (Cavassim et al., 2020). We therefore used "Rh" types to identify analogous replicons in the different bacteria (Table 4 and Supplementary Table 12). We found plenty of evidence for variations and frequent rearrangements between replicons in these genomes. Most of the Vaf10, Vaf108, BIHB1217, UPM791, and TOM plasmids shared homologies with more than one 3841 plasmid, revealing that replicons (and particularly the distribution of sequences among 
TABLE 4 | Putative functions and replicon location of genes associated with the EPC phenotypes in pea/lentil, identified by the comparative genomic analyses.

\begin{tabular}{|c|c|c|c|c|c|c|c|c|}
\hline \multirow[b]{2}{*}{ Gene identifier } & \multirow[b]{2}{*}{ EPC component } & \multirow[b]{2}{*}{ Putative function } & \multicolumn{6}{|c|}{ Genomic location } \\
\hline & & & 3841 & Vaf10 & Vaf-108 & BIHB1217 & UPM791 & TOM \\
\hline PK1 & CFN & hypothetical protein & NA & Rh08 & Rh08 & Rh08 & Rh08 & NA \\
\hline PK2 & CFN & hypothetical protein & NA & NA & $\mathrm{Rh02}$ & Rh02 & $\mathrm{Rh02}$ & NA \\
\hline $\mathrm{Pl} 1$ & CFN & putative transmembrane & chr & NA & NA & chr & chr & NA \\
\hline $\mathrm{Pl} 2$ & CFN & putative transmembrane & chr & NA & NA & chr & chr & NA \\
\hline PI3 & CFN & hypothetical protein & chr & chr & NA & chr & chr & NA \\
\hline $\mathrm{Pl} 4$ & CFN & RelE/StbE replicon stabilization toxin & chr & chr & NA & chr & chr & NA \\
\hline $\mathrm{Pl} 5$ & CFN & hypothetical protein & chr & NA & NA & chr & chr & NA \\
\hline PI6 & CFN & amidinotransferase & chr & NA & NA & chr & chr & NA \\
\hline $\mathrm{PI} 7$ & CFN & amidinotransferase & chr & NA & NA & chr & chr & NA \\
\hline PI8 & CFN & miscellaneous & chr & NA & NA & chr & chr & NA \\
\hline PI9 & CFN & putative transcriptional regulator & $\mathrm{RhO3}$ & Rh08 & $\mathrm{Rh01}$ & Rh08 & Rh08 & NA \\
\hline $\mathrm{PI} 10$ & CFN & hypothetical protein & $\mathrm{RhO3}$ & Rh08 & $\mathrm{Rh01}$ & $\mathrm{Rh08}$ & $\mathrm{Rh08}$ & NA \\
\hline Pl11 & CFN & uracil/thymine DNA glycolase & $\mathrm{RhO2}$ & NA & NA & Rh02 & Rh02 & NA \\
\hline $\mathrm{Pl} 12$ & CFN & L-2-hydroxyglutarate oxidase & Rh05 & NA & NA & $\mathrm{Rh04a}$ & $\mathrm{Rh04a}$ & NA \\
\hline $\mathrm{Pl} 13$ & CFN & L-proline/glycine betaine transporter ProP & Rh05 & NA & NA & Rh01 & Rh01 & NA \\
\hline PA1 & CFN & hypothetical protein & NA & chr & chr & NA & NA & NA \\
\hline PA2 & CFN & Delta-9 fatty acid desaturase & NA & $\mathrm{chr}$ & NA & NA & NA & NA \\
\hline PA3 & CFN & Putative membrane-bound ClpP-class protease & chr & chr & chr & chr & chr & NA \\
\hline PA4 & CFN & hypothetical protein & $\mathrm{RhO2}$ & NA & $\mathrm{RhO2}$ & $\mathrm{RhO2}$ & $\mathrm{RhO2}$ & NA \\
\hline PA5 & CFN & hypothetical protein & chr & chr & chr & $\mathrm{Rh} 01$ & NA & NA \\
\hline PA6 & CFN & hypothetical protein & NA & Rh08 & Rh17 & NA & NA & NA \\
\hline LA1 & CFN & TPR domain protein in aerotolerance operon & chr & Rh12 & NA & chr & NA & NA \\
\hline LA2 & CFN & BatA & chr & Rh12 & $\mathrm{Rh01}$ & chr & NA & NA \\
\hline LA3 & CFN & Possible Neuromedin U precursor & chr & Rh12 & NA & chr & NA & NA \\
\hline LA4 & CFN & Enoyl-acyl-carrier-protein reductase & chr & NA & NA & NA & NA & NA \\
\hline LA5 & CFN & hypothetical protein & Rh01 & Rh01 & NA & $\mathrm{Rh01}$ & NA & Rh01 \\
\hline LA6 & CFN & hypothetical protein & chr & NA & NA & chr & chr & NA \\
\hline LR1 & CFN & Cell filamentation protein fic & chr & Rh08 & chr & chr & chr & NA \\
\hline LR2 & CFN & VapC toxin protein antagonist & $\mathrm{Rh01}$ & NA & Rh01 & NA & NA & Rh01 \\
\hline LF1 & CFN & Polyhydroxyalkanoic acid synthase & $\mathrm{RhO3}$ & Rh17 & Rh17 & Rh08 & NA & NA \\
\hline LF2 & CFN & Acetyl-coenzyme A synthetase & Rh03 & Rh01 & NA & Rh08 & NA & NA \\
\hline LF3 & CFN & Homoserine O-acetyltransferase & $\mathrm{RhO3}$ & Rh01 & NA & Rh08 & NA & NA \\
\hline LF4 & CFN & putative dehalogenase-hydrolase & $\mathrm{RhO3}$ & Rh01 & NA & $\mathrm{Rh08}$ & NA & NA \\
\hline LF5 & CFN & hypothetical protein & $\mathrm{RhO3}$ & Rh01 & $\mathrm{Rh01}$ & $\mathrm{Rh08}$ & NA & NA \\
\hline LF6 & CFN & hypothetical protein & $\mathrm{RhO3}$ & Rh01 & $\mathrm{Rh01}$ & $\mathrm{Rh08}$ & NA & NA \\
\hline LF7 & CFN & hypothetical protein & $\mathrm{RhO3}$ & Rh01 & NA & $\mathrm{Rh08}$ & NA & NA \\
\hline PAFN1 & AFN & hypothetical protein & NA & Rh01 & $\mathrm{Rh01}$ & NA & NA & Rh01 \\
\hline PAFN2 & AFN & MFS permease & chr & chr & chr & NA & NA & chr \\
\hline PAFN3 & AFN & hypothetical protein & NA & NA & NA & NA & NA & chr \\
\hline PAFN4 & AFN & Beta-galactosidase & chr & NA & chr & NA & NA & chr \\
\hline PAFN5 & AFN & Beta-galactosidase & chr & NA & chr & NA & NA & chr \\
\hline PAFN6 & AFN & CobN component of cobalt chelatase & chr & chr & NA & NA & NA & chr \\
\hline PAFN7 & AFN & hypothetical protein & NA & Rh12 & NA & Rh06 & NA & Rh06 \\
\hline PAFN8 & AFN & hypothetical protein & Rh12 & Rh12 & $\mathrm{Rh} 01$ & $\mathrm{Rh06}$ & Rh12 & Rh06 \\
\hline PAFN9 & AFN & Bll0066 protein & Rh12 & Rh12 & Rh01 & Rh06 & Rh12 & Rh06 \\
\hline PAFN10 & AFN & hypothetical protein & Rh12 & Rh12 & Rh01 & Rh06 & Rh12 & Rh06 \\
\hline PAFN11 & AFN & Probably methylase/helicase & Rh12 & Rh12 & Rh01 & Rh06 & NA & Rh06 \\
\hline PAFN12 & AFN & nodT RND efflux system & $\mathrm{Rh03}$ & Rh01 & Rh08 & Rh08 & NA & Rh06 \\
\hline PAFN13 & AFN & Alpha-aspartyl dipeptidase Peptidase E & chr & chr & chr & NA & NA & chr \\
\hline PAFN14 & AFN & putative transmembrane protein & chr & chr & chr & chr & chr & chr \\
\hline PAFN15 & AFN & PE-PGRS FAMILY PROTEIN & chr & chr & NA & NA & NA & chr \\
\hline
\end{tabular}




\begin{tabular}{|c|c|c|c|c|c|c|c|c|}
\hline Gene identifier & EPC component & Putative function & 3841 & Vaf10 & Vaf-108 & BIHB1217 & UPM791 & TOM \\
\hline PAFN17 & AFN & Bll0066 protein & Rh12 & Rh12 & Rh01 & Rh06 & Rh12 & Rh03 \\
\hline
\end{tabular}

Replicons are classified ('chr' chromosome or 'rh' type plasmid) based on sequence homology to repABC genes as described by Cavassim et al., 2020. NA indicates no significant homologous sequence. Gene identifiers referred to the host and the EPC component (CFN or AFN). Gene identified by comparing host-compatible bacteria displaying contrasted level of competitiveness were labelled as CFN and associated to the host used for the comparison: pea cv. 'Kayanne' (PK), pea CV. 'Isard' (PI), pea Cv. 'Afghanistan' (PA), lentil cv. 'Anicia' (LA), lentil cv. 'Rosana' (LR) and lentil CV. 'Flora' (LF). Gene identified by comparing R/v strains displaying contrasted ability to form nodule with pea cV 'Afghanistan' were labelled AFN (PAFN). More details are provided in Supplementary Table 14.

replicons) vary greatly among the various bacteria. For example, in strain BIHB1217, plasmid pPR4 (Rh08) shared sequence homologies with the pRL7 (Rh12), pRL8 (Rh13), and pRL10 (Rh03) plasmids of strain 3841. In the Vaf-108 genome, the chromosome shared homologies with both the 3841 chromosome and the pRL10 plasmid, indicating that rearrangements were probably not restricted to plasmids. This fluidity of the accessory genome was very apparent when we examined the location of the genes that showed significant associations with EPC (Table 4 and Supplementary Tables 13, 14). The genes PI9 and PI10 were always adjacent in the fully assembled genomes: they belonged to Rh01 plasmid in Vaf-108, to Rh03 in 3841, and to Rh08 in Vaf-10, BIHB1217 and UPM791. In the genomes of BIHB1217 and UPM791, the PI12 and PI13 genes belonged to Rh04a, but in 3841 to Rh05. The genes PEPC8-10 and PEPC17 were all on Rh12 in 3841, Vaf-10 and UPM791, on Rh01 in Vaf-108, on Rh06 in BIHB1217. In the strain TOM, PEPC8-10 were on Rh06, but PEPC17 was on Rh03. These multiple examples of genome rearrangement, and numerous others, indicated that the replicon location of a gene could not be reliably inferred from its location in another strain.

\section{DISCUSSION}

This study addressed the question of partner choice at a population level, when multiple compatible host-symbiont associations are possible. In natural soil conditions, the presence of multiple compatible symbiont strains for a given host is generally the rule rather than the exception (Checcucci et al., 2017; Ji et al., 2017; Irisarri et al., 2019; Younginger and Friesen, 2019). In such conditions, the partner choice cannot be simply deduced from the capacities of individual partners but must be analyzed in the context of competition between the various potential associations. As the capacity of symbionts to drive efficient $\mathrm{N}_{2}$ fixation activity is variable, this has clearly important consequences for the benefit of symbiosis to the plant. Indeed, several attempts to improve symbiotic traits by inoculation of "elite" rhizobia, selected for their high SNF in individual association with a compatible legume host, have often failed due to outcompetition by endogenous strains already present in the soil (Triplett and Sadowsky, 1992; Fesenko et al., 1995). Improving the knowledge of mechanisms involved in the competitive success of symbiotic association during the EPC stage is necessary to select new "elite" bacteria and design successful inoculation strategies. However, in this study, the plants were cultivated in a standard substrate in controlled laboratory conditions that may differ from a natural ecosystem (which contained generally more complex bacterial populations). Increasing the complexity of the biological system and exploring the impact of soil environment on EPC deserve further investigations.

\section{A Metabarcoding Approach to Characterize EPC}

Previous studies estimated the competitiveness of rhizobial isolates individually by co-inoculating a host plant with both a strain of interest and a reference strain (Bourion et al., 2017; Boivin et al., 2020). Selecting antibiotic resistant mutants, or introducing fluorescent markers on plasmids, greatly improved the recognition of bacteria in these simple mixtures, but could modify the competitiveness of the bacteria of interest (Amarger et al., 1981; Melkonian et al., 2014; Westhoek et al., 2017). Moreover, these techniques hardly consider the effect of multiple interactions. Construction of bacterial populations in which each strain can be individually quantified, allows the study of complex interactions that cannot be revealed when single strains are competed separately with a reference strain (Epstein et al., 2018; Carlström et al., 2019; Boivin and Lepetit, 2020). The use of the DNA metabarcoding strategy allowed EPC to be evaluated after co-inoculation of roots with large populations of diverse unmodified rhizobia. Previous studies have estimated rhizobial EPC by the number of nodules formed with the bacteria of interest as compared to total nodule number on the plant root system. Estimating the EPC by a DNA metabarcoding approach globally quantifies rhizobia interacting with the plant. However, differential nodule growth, or differential levels of bacteroid endoreduplication, of the various bacteria may result in differences between these two estimates (Kazmierczak et al., 2017). To minimize this potential difference, we applied DNA metabarcoding on roots at an early stage of interaction, before these processes become prominent. This metabarcoding strategy was able to confirm and extend previous data already obtained by earlier methods: (1) in pea cv Afghanistan the host specific nodulation of some strains that produce NodX, (2) in fababean the high EPC of Nod type B strains. In both cases, coinoculation of the hosts by the core collection of strains resulted in the expected EPC profiles, validating our strategy. Our global approach to measure EPC, addressed at the whole root system 
level, was able to confirm conclusions obtained by earlier timeconsuming experimental strategy addressed at the nodule level with a limited number of strains (Boivin et al., 2020).

\section{A Representative Core Collection of Fabeae Symbionts}

Sequencing 48 additional genomes of $R l v$ strains isolated from Fabeae root nodules of various geographical origins allowed us to characterize and extend our current knowledge of the viciae symbiovar and genospecies diversity, increasing the 73 $R l v$ genome sequences available in GenBank at the beginning of this study. Genospecies were defined based on established criteria for bacteria in general as well as for Rhizobium species (Jain et al., 2018; de Lajudie et al., 2019; Young et al., 2021). All the bacteria shared closely related nod gene sequences typical of the symbiovar viciae. Their core genes placed the majority of them within genospecies in the $R$. leguminosarum species complex (Young et al., 2021), but several isolates were genetically distant from these (ANI $<90 \%)$ and belonged to other species in the wider R. leguminosarum - R. etli clade (Supplementary Table 1). We selected a set of 32 bacteria, representative of the known genomic diversity of Fabeae symbionts, to study hostspecific EPC. Individuals within the bacterial mixture have been discriminated by a DNA barcode located in the nodD gene of the symbiotic plasmid. We assumed that the number of barcodes of each strain was proportional to their abundancy in the nodules of the root system. This nodD metabarcoding enabled us to explore much of the intraspecific variability of the symbiovar. Nevertheless, within a few bacterial subgroups, the barcode diversity is limited. Namely, the $R l v$ strains carrying the Nod type B1 shared an identical barcode and only one strain could be included in the EPC study although strains of this subgroup may display genomic variations. The design and the high-throughput sequencing of a longer barcode might improve the resolution of the technique in the near future.

\section{Inoculation of RIV Core Collection on Various Hosts Revealed Host-Specific EPC}

Co-inoculation of the core collection of $32 \mathrm{Rlv}$ strains, in mixture, on Pisum sativum, Vicia faba, and Lens culinaris genotypes revealed contrasted host-specific EPC profiles. Profiles varied according to the bacterium, the plant species and the plant genotype. They resulted from the different capacities of the various plant-microbe partnerships. Because bacteria were amplified separately and were present at high density in the inoculum ( $>10^{7} \mathrm{CFU} / \mathrm{mL}$ ), these contrasted EPC profiles were unlikely to be due to microbe-microbe interactions resulting in differential bacterial multiplication in the rhizosphere, possibly limiting root infection. This study identified bacteria of the $R l v$ core collection that displayed host-specific EPC with diverse Vicia faba, Pisum sativum, and Lens culinaris genotypes. In a few cases, the partner choice was the result of a specific ability to form nodules that was confined to certain strains (namely Nod type B bacteria with the nodX gene and pea cV "Afghanistan") allowing them to associate with this host while others could not.
However, in most case $R l v$ strains have abilities to associate with all the Fabeae hosts but display different levels of EPC when coinoculated in mixture, resulting in contrasted responses of the various hosts to the co-inoculation with the Rlv core collection. This offered the opportunity to associate ability to nodulate and EPC traits of the bacteria with specific genome variations.

\section{Both the nodX Gene and Nod Type B-Related Factors Are Necessary to Confer Ability to Form Nodules With the Pisum sativum Cultivar "Afghanistan"}

The co-inoculation strategy confirmed earlier data indicating that only $R l v$ bacteria carrying the nodX gene can nodulate with the pea cultivar "Afghanistan," resulting in a highly specific association profile, consistent with a restriction of host specificity in this particular plant genotype (Davis et al., 1988; Firmin et al., 1993). However, this study revealed unexpected complexities of the nodX/Sym 2 interaction. Surprisingly many $R l v$ genomes (22\%), belonging to both A and B nod types, have a nodX gene. The corresponding bacteria were isolated from different Fabeae host plants and have multiple geographical origins around the world, including locations where relatives of cv "Afghanistan" are not expected to be present. Nodulation tests confirmed that the nodX gene from a Nod type A strain (i.e., strain P221) is able to complement a Nod type B strain lacking nodX and allow the transconjugant to nodulate cv. "Afghanistan" even though the donor cannot. This rules out the hypothesis of a non-functional copy of nodX in Nod type A strains. If the nodX function is related to the host-specific nodulation with the pea cv "Afghanistan," why has the gene been maintained in the Nod type A bacteria? We suggest that other unknown functions might explain the conservation of this gene within natural $R l v$ populations. Interestingly, the nodX gene is also present in $R$. leguminosarum symbiovar trifolii rhizobia, which nodulate clovers but are unable to nodulate any pea genotype, including cv "Afghanistan" (Ovtsyna et al., 1999). Other surprising results were that (1) the nodX gene was not sufficient alone to confer ability form root nodules with the cultivar cv "Afghanistan" to all Rlv bacteria, and (2) other genetic determinants specific to the nod type B strains were also required together with nodX. Therefore, the control of the host-specific nodulation with the cv "Afghanistan" in Rlv might be more complex than deduced from earlier studies (Davis et al., 1988; Firmin et al., 1993). Finally, this study showed that the ability to nodulate conferred by both the Nod type B and the presence of nodX does not guarantee preferential EPC when multiple compatible partner are co-inoculated. A striking example is the TOM strain, the well-studied reference symbiont of the pea cv "Afghanistan." This strain, able to form nodule with this cultivar when mono-inoculated, was included in the co-inoculation mixture. However, it was detected at very low level in the symbiotic roots because completely outcompeted by other Nod type B Rlv strains that also have the nodX gene. This revealed that this subgroup of strains with specific capacities to associate with this host gathered strains with contrasted levels of competitiveness to form nodules. 


\section{Host-Specific EPC Is Associated With Different Genomic Regions of R/v Bacteria}

Our metabarcoding strategy on Fabeae plants, inoculated with the population of the Rlv core collection, was able to confirm our previous results indicating that host-specific EPC was associated with the $R l v$ Nod types A and B with pea and fababean, respectively (Boivin et al., 2020). Since nod genes are directly related to NF production and secretion (Mergaert et al., 1997), the associations between the Nod types/groups and EPC deserves further investigations. The quantity and particularly the quality of the NF cocktail produced may contribute to the level of competitiveness of the bacteria: this is an interesting hypothesis that will need further investigations. We obtained, in this study, new evidence indicating that the EPC with lentil was associated with the genospecies, but poorly with the Nod type or the Nod group, in contrast to the results for pea and fababean. Indeed, different genetic determinants, mainly located on the chromosome, controlled EPC with lentil. This confirms the report of Jorrin and Imperial (2015) suggesting that lentil may be less selective than pea and fababean for rhizobial partner choice. Nevertheless, despite these global trends, the genetic control of EPC was always complex since, for all plant hosts, we found associations of EPC with both Nod groups and genospecies, as well as an interaction. An unexpected result was the observation of a high EPC of the 3841 bacteria with pea. The 3841 strain is the unique bacterium of Nod group B1 present in the core collection. Our previous investigation on natural isolates in comparison with a reference strain indicated that bacteria of this group B1 were generally competitive with fababean but poorly competitive with pea (Boivin et al., 2020). This different behavior of the strain 3841 as compare to natural isolates deserves further investigation with particular emphasis on the association with the pea EPC phenotype. Because the strain 3841, initially isolated from pea root nodules, was cultivated in laboratories for many years, we cannot rule out that this particular phenotype may be related to unknown selection processes. A similar comment could be done with the strain TOM which was also isolated long time ago. It could be speculate that laboratory selection could have produced the opposite effect compare to 3841 , and reduced its competitiveness with its original pea host. Nevertheless, the strategy of comparing genomes between competitive and uncompetitive strains allowed us to identify, for each plant genotype, regions of the bacterial genomes associated with hostspecific EPC. The assignment of the identified genomic regions to a particular replicon deserves further study. As the knowledge of $R$. leguminosarum genomes is expanding, increasing evidence indicates that plasmid number, size and composition vary greatly in this bacterial species (Mazurier and Laguerre, 1997; Laguerre et al., 2003; Kumar et al., 2015; Cavassim et al., 2020). Different bacteria belonging to the same symbiovar share homologous sequences, organized differently in their diverse replicons. There is evidence that genetic rearrangements may occur even between plasmids and chromosome. The emerging picture revealed a high fluidity between $R$. leguminosarum replicons that argued against our first attempt to assign genomic regions to replicons by homology with a reference genome. More recently, the intensity of the rearrangements and the complexity of the evolution Rhizobium plasmids as compared to chromosome, as well as symbiotic clusters as compared to other accessory clusters, have been evidenced using whole genome analysis (Li et al., 2020). However, the fluidity of the accessory genome is essential for the genetic association approach that we have taken in this study, which requires a certain degree of independence between loci in order to associate phenotypes with individual genes rather than with whole replicons or large blocks of coinherited genes.

\section{Candidate Genes Involved in Host-Specific EPC}

As comparative studies yielded multiple potential genomic regions associated with EPC, it is tempting to hypothesize that multiple genes control this trait. Some protein sequences have functions already associated with EPC. For instance, the rhizobial nodT gene, putatively involved in the secretion of nod factor (Rivilla et al., 1995), as well as components of Vap toxin/antitoxin systems (Lipuma et al., 2014), were already suspected to be associated with EPC with pea or fababean in a previous study based on co-inoculation experiments with a reference strain (Boivin et al., 2020). Here, we identified new candidate genes associated with EPC. However, these genetic associations have to be validated as it may be related to neighboring loci. Therefore, further investigations are required to demonstrate the direct role of these genes in EPC. Reverse genetics studies with different combinations of alleles will be required to validate their potential biological function in host-specific EPC of $R l v$ strains. The expression of the candidate genes could reveal differential expression depending on environmental conditions and/or host specificities (Fagorzi et al., 2021). Nevertheless, these sequences are valuable markers to select competitive $R l v$ strains with pea and/or lentil and pave the way for the identification of the $R l v$ genes controlling EPC. This knowledge opens new perspectives to select rhizobia and legumes, by genetic association, for new inoculation strategies that will ultimately improve the agro-ecological services of Fabeae legume holobionts (Burghardt, 2020). Moreover, this metabarcoding strategy coupled with complex inocula could be also be extended to other beneficial or pathogenic plant-microbe interactions.

\section{DATA AVAILABILITY STATEMENT}

New bacterial genomes sequences (48) are described in the BioProject PRJNA579265 that gathered 48 BioSamples (https://www.ncbi.nlm.nih.gov/). Genome accession numbers of these genome sequences are in the Supplementary Table 1, together with the accessions numbers of genomes already described in previous studies included in our 
analysis. DNA NodD Metabarcoding sequences are described in the BioProject PRJNA744092 that gathered 36 BioSamples (https: //www.ncbi.nlm.nih.gov/). The BioProject and the BioSamples are described in the same way as in the article. Each BioSamples has two fastq files due to paired-end sequencing (raw data). The 30 barcodes sequences of the core-collection bacteria are presented in Supplementary Table 3. Numbers of barcodes in biological samples after filtering by the pipeline described in the section "Materials and Methods" of the article is presented in Supplementary Table 4.

\section{AUTHOR CONTRIBUTIONS}

ML and SB designed the research and wrote the manuscript with the contribution of PY. ML, SB, PY, JW, and SM provided rhizobial strains. SB, FD, MP, MatT, and FM performed the experiments. FM, MarT, and SB performed genomic and metabarcoding in silico analysis. SB, ML, FM, FD, and PY analyzed the data. All authors contributed to the article and approved the submitted version.

\section{FUNDING}

This work was supported by the GRaSP grant (ANR-16-CE200021) of the Agence Nationale pour la Recherche (ANR).

\section{ACKNOWLEDGMENTS}

We acknowledge Markus Braun (Heidelberg University), Xinhua Sui and Changfu Tian (China Agricultural University, Beijing), Anna Skorupska and Andrzej Mazur (Medical University of Lublin), and Juan Imperial (Instituto de Ciencias Agrarias, Madrid) for providing some of the rhizobial strains included in this study, as well as the Genotoul GeT-PlaGe platform of Toulouse for the Illumina MiSeq sequencing. We thank Laurence Dupont for critical reading of the manuscript.

\section{REFERENCES}

Amarger, N. (1981). Competition for nodule formation between effective and ineffective strains of Rhizobium meliloti. Soil Biol. Biochem. 13, 475-480. doi: 10.1016/0038-0717(81)90037-7

Baev, N., Schultze, M., Barlier, I., Ha, D. C., Virelizier, H., Kondorosi, E., et al. (1992). Rhizobium nodM and nodN genes are common nod genes: nodM encodes functions for efficiency of nod signal production and bacteroid maturation. J. Bacteriol. 174, 7555-7565.

Boivin, S., and Lepetit, M. (2020). "Chapter Eleven - Partner preference in the legume-rhizobia symbiosis and impact on legume inoculation strategies," in Advances in Botanical Research Regulation of Nitrogen-Fixing Symbioses in Legumes, eds P. Frendo, F. Frugier, and C. Masson-Boivin (Cambridge, MA: Academic Press), 323-348.

Boivin, S., Mah, F. D., Pervent, M., Tancelin, M., Tauzin, M., Wielbo, J., et al. (2020). Genetic variation in host-specific competitiveness of the symbiont Rhizobium leguminosarum symbiovar viciae. Preprints doi: 10.22541/au. 159237007.72934061

\section{SUPPLEMENTARY MATERIAL}

The Supplementary Material for this article can be found online at: https://www.frontiersin.org/articles/10.3389/fpls.2021. 719987/full\#supplementary-material

Supplementary Figure 1 | Variation of the EPC index.

Supplementary Figure 2 | NodD309 barcode diversity among Rhizobium leguminosarum sv. viciae.

Supplementary Table 1 | Genomic data of the sequenced R/V bacteria.

Supplementary Table 2 | Primers used and PCR conditions for metabarcoding.

Supplementary Table $\mathbf{3}$ | NodD309 sequences of the 32 rhizobia included in the RIV core collection.

Supplementary Table 4 | Read numbers in each sample after quality filtering.

Supplementary Table $\mathbf{5}$ | EPC indexes for each of the plant/rhizobia pairs.

Supplementary Table 6 | Genospecies and Nod group combinations in the initial rhizobial collection and within the core-collection.

Supplementary Table 7 | Clusters of RIV bacteria of the core collection, gathered on the basis of the EPC profiles of the Figure $\mathbf{3}$.

Supplementary Table 8 | Average Nucleotide Identity (ANI) between the 121 genomes of R/v, as well as Sinorhizobium meliloti Sm1021, R/ sv trifolii WSM1689 and RI sv phaseoli Rip4292.

Supplementary Table 9 | Presence/absence of genomic regions associated with EPC phenotypes in pea, fababean, and lentil.

Supplementary Table 10 | Mono-inoculation of the Pisum sativum cv "Afghanistan" with some Nod types A and B NodX-R/v strains, included in the R/V core collection.

Supplementary Table 11 | Presence/absence of genomic regions in Nod-type A and Nod-type B R/v strains carrying NodX, associated with an EPC with Pisum sativum cv "Afghanistan".

Supplementary Table 12 | Global rearrangements of plasmids/contigs between reference strains, in comparison with 3841 .

Supplementary Table 13 | Genomic organization of contigs containing genes associated with EPC, compared to 3841.

Supplementary Table 14 | Putative functions and locations of genes associated with EPC from the comparative genomic analyses.

Bourion, V., Heulin-Gotty, K., Aubert, V., Tisseyre, P., Chabert-Martinello, M., Pervent, M., et al. (2017). Co-inoculation of a pea core-collection with diverse rhizobial strains shows competitiveness for nodulation and efficiency of nitrogen fixation are distinct traits in the interaction. Front. Plant Sci. 8:2249. doi: $10.3389 /$ fpls.2017.02249

Burghardt, L. T. (2020). Evolving together, evolving apart: measuring the fitness of rhizobial bacteria in and out of symbiosis with leguminous plants. New Phytol. 228, 28-34. doi: 10.1111/nph.16045

Burghardt, L. T., Epstein, B., Guhlin, J., Nelson, M. S., Taylor, M. R., Young, N. D., et al. (2018). Select and resequence reveals relative fitness of bacteria in symbiotic and free-living environments. Proc. Natl. Acad. Sci. U.S.A. 115, 2425-2430. doi: 10.1073/pnas.1714246115

Carlström, C. I., Field, C. M., Bortfeld-Miller, M., Müller, B., Sunagawa, S., and Vorholt, J. A. (2019). Synthetic microbiota reveal priority effects and keystone strains in the Arabidopsis phyllosphere. Nat. Ecol. Evol. 3, 1445-1454. doi: 10.1038/s41559-019-0994-z

Catoira, R., Galera, C., de Billy, F., Penmetsa, R. V., Journet, E. P., Maillet, F., et al. (2000). Four genes of Medicago truncatula controlling components of a nod 
factor transduction pathway. Plant Cell 12, 1647-1666. doi: 10.1105/tpc.12.9. 1647

Cavassim, M. I. A., Moeskjær, S., Moslemi, C., Fields, B., Bachmann, A., Vilhjálmsson, B. J., et al. (2020). Symbiosis genes show a unique pattern of introgression and selection within a Rhizobium leguminosarum species complex. Microb. Genom 6:e000351. doi: 10.1099/mgen.0.000 351

Checcucci, A., DiCenzo, G. C., Bazzicalupo, M., and Mengoni, A. (2017). Trade, diplomacy, and warfare: the quest for elite rhizobia inoculant strains. Front. Microbiol. 8:2207. doi: 10.3389/fmicb.2017.02207

Darling, A. C. E., Mau, B., Blattner, F. R., and Perna, N. T. (2004). Mauve: multiple alignment of conserved genomic sequence with rearrangements. Genome Res. 14, 1394-1403. doi: 10.1101/gr.2289704

Davis, E. O., Evans, I. J., and Johnston, A. W. (1988). Identification of nodX, a gene that allows Rhizobium leguminosarum biovar viciae strain TOM to nodulate Afghanistan peas. Mol. Gen. Genet. 212, 531-535. doi: 10.1007/bf00330860

de Lajudie, P. M., Andrews, M., Ardley, J., Eardly, B., Jumas-Bilak, E., Kuzmanoviæ, N., et al. (2019). Minimal standards for the description of new genera and species of rhizobia and agrobacteria. Int. J. Syst. Evolutionary Microbiol. 69, 1852-1863. doi: 10.1099/ijsem.0.003426

Dénarié, J., Debellé, F., and Rosenberg, C. (1992). Signaling and host range variation in nodulation. Annu. Rev. Microbiol. 46, 497-531. doi: 10.1146/ annurev.mi.46.100192.002433

Ditta, G., Stanfield, S., Corbin, D., and Helinski, D. R. (1980). Broad host range DNA cloning system for gram-negative bacteria: construction of a gene bank of Rhizobium meliloti. Proc. Natl. Acad. Sci. U.S.A. 77, 7347-7351. doi: 10.1073/ pnas.77.12.7347

Djordjevic, M. A., Schofield, P. R., and Rolfe, B. G. (1985). Tn5 mutagenesis of Rhizobium trifolii host-specific nodulation genes result in mutants with altered host-range ability. Molec. Gen. Genet. 200, 463-471. doi: 10.1007/BF00425732

Dombrecht, B., Vanderleyden, J., and Michiels, J. (2001). Stable RK2-derived cloning vectors for the analysis of gene expression and gene function in gramnegative bacteria. Mol. Plant Microbe Interact. 14, 426-430. doi: 10.1094/MPMI. 2001.14.3.426

Edgar, R. C., Haas, B. J., Clemente, J. C., Quince, C., and Knight, R. (2011). UCHIME improves sensitivity and speed of chimera detection. Bioinformatics 27, 2194-2200. doi: 10.1093/bioinformatics/btr381

Engler, C., Gruetzner, R., Kandzia, R., and Marillonnet, S. (2009). Golden gate shuffling: a one-pot DNA shuffling method based on type IIs restriction enzymes. PLoS One 4:e5553. doi: 10.1371/journal.pone.0005553

Epstein, B., Abou-Shanab, R. A. I., Shamseldin, A., Taylor, M. R., Guhlin, J., Burghardt, L. T., et al. (2018). Genome-Wide association analyses in the model Rhizobium ensifer meliloti. mSphere 3, e386-e318. doi: 10.1128/mSphere. 00386- 18

Fagorzi, C., Bacci, G., Huang, R., Cangioli, L., Checcucci, A., Fini, M., et al. (2021). Nonadditive transcriptomic signatures of genotype-by-genotype interactions during the initiation of Plant-Rhizobium symbiosis. mSystems 6, e974-e920. doi: 10.1128/mSystems.00974-20

Fesenko, A. N., Provorov, N. A., Orlova, I. F., Orlov, V. P., and Simarov, B. V. (1995). Selection of Rhizobium leguminosarum bv. viceae strains for inoculation of Pisum sativum L. cultivars: analysis of symbiotic efficiency and nodulation competitiveness. Plant Soil 172, 189-198. doi: 10.1007/BF00011321

Firmin, J. L., Wilson, K. E., Carlson, R. W., Davies, A. E., and Downie, J. A. (1993). Resistance to nodulation of cv Afghanistan peas is overcome by nodX, which mediates an O-acetylation of the Rhizobium leguminosarum lipooligosaccharide nodulation factor. Mol. Microbiol. 10, 351-360. doi: 10.1111/ j.1365-2958.1993.tb01961.x

Fliegmann, J., Jauneau, A., Pichereaux, C., Rosenberg, C., Gasciolli, V., Timmers, A. C. J., et al. (2016). LYR3, a high-affinity LCO-binding protein of Medicago truncatula, interacts with LYK3, a key symbiotic receptor. FEBS Lett. 590, 1477-1487. doi: 10.1002/1873-3468.12191

Hogg, B., Davies, A. E., Wilson, K. E., Bisseling, T., and Downie, J. A. (2002). Competitive nodulation blocking of cv Afghanistan pea is related to high levels of nodulation factors made by some strains of Rhizobium leguminosarum bv. viciae. Mol. Plant Microbe Interact. 15, 60-68. doi: 10.1094/MPMI.2002.15.1.60

Irisarri, P., Cardozo, G., Tartaglia, C., Reyno, R., Gutiérrez, P., Lattanzi, F. A., et al. (2019). Selection of competitive and efficient rhizobia strains for white clover. Front. Microbiol. 10:768. doi: 10.3389/fmicb.2019.00768
Jain, C., Rodriguez-R, L. M., Phillippy, A. M., Konstantinidis, K. T., and Aluru, S. (2018). High throughput ANI analysis of 90K prokaryotic genomes reveals clear species boundaries. Nat. Commun. 9:5114. doi: 10.1038/s41467-018-07641-9

Janczarek, M., Rachwał, K., Marzec, A., Grządziel, J., and Palusińska-Szysz, M. (2015). Signal molecules and cell-surface components involved in early stages of the legume-rhizobium interactions. Appl. Soil Ecol. 85, 94-113. doi: 10.1016/ j.apsoil.2014.08.010

Ji, Z. J., Yan, H., Cui, Q. G., Wang, E. T., Chen, W. F., and Chen, W. X. (2017). Competition between rhizobia under different environmental conditions affects the nodulation of a legume. Syst. Appl. Microbiol. 40, 114-119. doi: 10.1016/j. syapm.2016.12.003

Jorrin, B., and Imperial, J. (2015). Population genomics analysis of legume host preference for specific rhizobial genotypes in the Rhizobium leguminosarum bv. viciae Symbioses. Mol. Plant Microbe Interact. 28, 310-318. doi: 10.1094/ MPMI-09-14-0296-FI

Kawaharada, Y., Kelly, S., Nielsen, M. W., Hjuler, C. T., Gysel, K., Muszyński, A., et al. (2015). Receptor-mediated exopolysaccharide perception controls bacterial infection. Nature 523, 308-312. doi: 10.1038/nature14611

Kazmierczak, T., Nagymihály, M., Lamouche, F., Barrière, Q., Guefrachi, I., Alunni, B., et al. (2017). Specific host-responsive associations between medicago truncatula accessions and sinorhizobium strains. Mol. Plant Microbe Interact. 30, 399-409. doi: 10.1094/MPMI-01-17-0009-R

Kolde, R. (2019). R Package Version 1.0.12. Available online at: https://CRAN.Rproject.org/package $=$ pheatmap

Kumar, N., Lad, G., Giuntini, E., Kaye, M. E., Udomwong, P., Shamsani, N. J., et al. (2015). Bacterial genospecies that are not ecologically coherent: population genomics of Rhizobium leguminosarum. Open Biol. 5:140133. doi: 10.1098/ rsob. 140133

Laguerre, G., Heulin-Gotty, K., Brunel, B., Klonowska, A., Le Quéré, A., Tillard, P., et al. (2012). Local and systemic N signaling are involved in Medicago truncatula preference for the most efficient Sinorhizobium symbiotic partners. New Phytol. 195, 437-449. doi: 10.1111/j.1469-8137.2012.04159.x

Laguerre, G., Louvrier, P., Allard, M.-R., and Amarger, N. (2003). Compatibility of rhizobial genotypes within natural populations of Rhizobium leguminosarum biovar viciae for nodulation of host legumes. Appl. Environ. Microbiol. 69, 2276-2283.

Lewis-Henderson, W. R., and Djordjevic, M. A. (1991). nodT, a positivelyacting cultivar specificity determinant controlling nodulation of Trifolium subterraneum by Rhizobium leguminosarum biovar trifolii. Plant Mol. Biol. 16, 515-526.

Lipuma, J., Cinege, G., Bodogai, M., Oláh, B., Kiers, A., Endre, G., et al. (2014). A vapBC-type toxin-antitoxin module of Sinorhizobium meliloti influences symbiotic efficiency and nodule senescence of Medicago sativa. Environ. Microbiol. 16, 3714-3729. doi: 10.1111/1462-2920. 12608

Li, X., Wang, H., Tong, W., Feng, L., Wang, L., Rahman, S. U., et al. (2020). Exploring the evolutionary dynamics of Rhizobium plasmids through bipartite network analysis. Environ. Microbiol. 22, 934-951. doi: 10.1111/1462-2920. 14762

Mahé, F., Rognes, T., Quince, C., Vargas, C., and Dunthorn, M. (2015). Swarm v2: highly-scalable and high-resolution amplicon clustering. PeerJ 3:e1420. doi: 10.7717/peerj. 1420

Martin, M. (2011). Cutadapt removes adapter sequences from high-throughput sequencing reads. EMBnet J. 17, 10-12. doi: 10.14806/ej.17.1.200

Mazurier, S.-I., and Laguerre, G. (1997). Unusual localization of nod and nif genes in Rhizobium leguminosarum bv. viciae. Canadian J. Microbiol. 43, 399-402. doi: 10.1139/m97-056

McAnulla, C., Edwards, A., Sanchez-Contreras, M., Sawers, R. G., and Downie, J. A. (2007). Quorum-sensing-regulated transcriptional initiation of plasmid transfer and replication genes in Rhizobium leguminosarum biovar viciae. Microbiology 153, 2074-2082. doi: 10.1099/mic.0.2007/007153-0

McKenzie, R. H., Middleton, A. B., Solberg, E. D., DeMulder, J., Flore, N., Clayton, G. W., et al. (2011). Response of pea to rhizobia inoculation and starter nitrogen in Alberta. Canadian J. Plant Sci. 81, 637-643. doi: 10.4141/P01006

Melkonian, R., Moulin, L., Béna, G., Tisseyre, P., Chaintreuil, C., Heulin, K., et al. (2014). The geographical patterns of symbiont diversity in the invasive legume Mimosa pudica can be explained by the competitiveness of its symbionts and by 
the host genotype. Environ. Microbiol. 16, 2099-2111. doi: 10.1111/1462-2920. 12286

Mendoza-Suárez, M. A., Geddes, B. A., Sánchez-Cañizares, C., Ramírez-González, R. H., Kirchhelle, C., Jorrin, B., et al. (2020). Optimizing Rhizobium-legume symbioses by simultaneous measurement of rhizobial competitiveness and N2 fixation in nodules. Proc. Natl. Acad. Sci. U.S.A. 117, 9822-9831. doi: 10.1073/ pnas. 1921225117

Mergaert, P., Van Montagu, M., and Holsters, M. (1997). Molecular mechanisms of Nod factor diversity. Mol. Microbiol. 25, 811-817.

Miwa, H., and Okazaki, S. (2017). How effectors promote beneficial interactions. Curr. Opin. Plant Biol. 38, 148-154. doi: 10.1016/j.pbi.2017.05.011

Moawad, H. A., Ellis, W. R., and Schmidt, E. L. (1984). Rhizosphere response as a factor in competition among three serogroups of indigenous Rhizobium japonicum for nodulation of field-grown soybeans. Appl. Environ. Microbiol. 47, 607-612.

Mutch, L. A., and Young, J. P. W. (2004). Diversity and specificity of Rhizobium leguminosarum biovar viciae on wild and cultivated legumes. Mol. Ecol. 13, 2435-2444. doi: 10.1111/j.1365-294X.2004.02259.x

Naamala, J., Jaiswal, S. K., and Dakora, F. D. (2016). Antibiotics resistance in Rhizobium: type, process, mechanism and benefit for agriculture. Curr. Microbiol. 72, 804-816. doi: 10.1007/s00284-016-1005-0

Oldroyd, G. E. D., Murray, J. D., Poole, P. S., and Downie, J. A. (2011). The rules of engagement in the legume-rhizobial symbiosis. Annu. Rev. Genet. 45, 119-144. doi: 10.1146/annurev-genet-110410-132549

Ovtsyna, A. O., Rademaker, G.-J., Esser, E., Weinman, J., Rolfe, B. G., Tikhonovich, I. A., et al. (1999). Comparison of characteristics of the nodX genes from various Rhizobium leguminosarum strains. MPMI 12, 252-258. doi: 10.1094/MPMI. 1999.12.3.252

Regus, J. U., Quides, K. W., O’Neill, M. R., Suzuki, R., Savory, E. A., Chang, J. H., et al. (2017). Cell autonomous sanctions in legumes target ineffective rhizobia in nodules with mixed infections. Am. J. Bot. 104, 1299-1312. doi: 10.3732/ajb.1700165

Rivilla, R., Sutton, J. M., and Downie, J. A. (1995). Rhizobium leguminosarum NodT is related to a family of outer-membrane transport proteins that includes TolC. PrtF, CyaE and AprF. Gene 161, 27-31.

Robleto, E. A., Scupham, A. J., and Triplett, E. W. (1997). Trifolitoxin production in Rhizobium etli strain CE3 increases competitiveness for rhizosphere colonization and root nodulation of phaseolus vulgaris in soil. MPMI 10, 228-233. doi: 10.1094/MPMI.1997.10.2.228

Rogel, M. A., Ormeno-Orrillo, E., and Romero, E. M. (2011). Symbiovars in rhizobia reflect bacterial adaptation to legumes. Systematic Appl. Microbiol. 34, 96-104.

Rognes, T., Flouri, T., Nichols, B., Quince, C., and Mahé, F. (2016). VSEARCH: a versatile open source tool for metagenomics. PeerJ 4:e2584. doi: 10.7717/peerj. 2584

Sallet, E., Gouzy, J., and Schiex, T. (2014). EuGene-PP: a next-generation automated annotation pipeline for prokaryotic genomes. Bioinformatics 30, 2659-2661. doi: 10.1093/bioinformatics/btu366

Sevin-Pujol, A., Sicard, M., Rosenberg, C., Auriac, M.-C., Lepage, A., Niebel, A., et al. (2017). Development of a GAL4-VP16/UAS trans-activation system for tissue specific expression in Medicago truncatula. PLoS One 12:e0188923. doi: 10.1371/journal.pone.0188923

Sulima, A. S., Zhukov, V. A., Afonin, A. A., Zhernakov, A. I., Tikhonovich, I. A., and Lutova, L. A. (2017). Selection signatures in the first exon of paralogous receptor kinase genes from the Sym2 region of the pisum sativum L. genome. Front. Plant Sci. 8:1957. doi: 10.3389/fpls.2017. 01957
Surin, B. P., and Downie, J. A. (1988). Characterization of the Rhizobium leguminosarum genes nodLMN involved in efficient host-specific nodulation. Mol. Microbiol. 2, 173-183.

Triplett, E. W., and Sadowsky, M. J. (1992). Genetics of competition for nodulation of legumes. Annu. Rev. Microbiol. 46, 399-428. doi: 10.1146/annurev.mi.46. 100192.002151

Walker, L., Lagunas, B., and Gifford, M. L. (2020). Determinants of host range specificity in legume-rhizobia symbiosis. Front. Microbiol. 11:585749. doi: 10. 3389/fmicb.2020.585749

Wang, Q., Liu, J., and Zhu, H. (2018). Genetic and molecular mechanisms underlying symbiotic specificity in legume-rhizobium interactions. Front. Plant. Sci. 9:313. doi: 10.3389/fpls.2018.00313

Wang, Q., Yang, S., Liu, J., Terecskei, K., Ábrahám, E., Gombár, A., et al. (2017). Host-secreted antimicrobial peptide enforces symbiotic selectivity in Medicago truncatula. Proc. Natl. Acad. Sci. U.S.A. 114, 6854-6859. doi: 10.1073/pnas. 1700715114

Westhoek, A., Clark, L. J., Culbert, M., Dalchau, N., Griffiths, M., Jorrin, B., et al. (2021). Conditional sanctioning in a legume-Rhizobium mutualism. Proc. Natl. Acad. Sci. U.S.A. 118:e2025760118. doi: 10.1073/pnas.2025760118

Westhoek, A., Field, E., Rehling, F., Mulley, G., Webb, I., Poole, P. S., et al. (2017). Policing the legume-Rhizobium symbiosis: a critical test of partner choice. Sci. Rep. 7:1419. doi: 10.1038/s41598-017-01634-2

Young, J. P. W. (1985). Rhizobium population genetics: enzyme polymorphism in isolates from peas, clover, beans and lucerne grown at the same site. Microbiology 131, 2399-2408.

Young, J. P. W. (2016). Bacteria are smartphones and mobile genes are apps. Trends Microbiol. 24, 931-932. doi: 10.1016/j.tim.2016.09.002

Young, J. P. W., Moeskjær, S., Afonin, A., Rahi, P., Maluk, M., James, E. K., et al. (2021). Defining the Rhizobium leguminosarum Species Complex. Genes (Basel) 12:111. doi: 10.3390/genes12010111

Younginger, B. S., and Friesen, M. L. (2019). Connecting signals and benefits through partner choice in plant-microbe interactions. FEMS Microbiol. Lett. 366:fnz217. doi: 10.1093/femsle/fnz217

Zézé, A., Mutch, L. A., and Young, J. P. (2001). Direct amplification of nodD from community DNA reveals the genetic diversity of Rhizobium leguminosarum in soil. Environ. Microbiol. 3, 363-370.

Zhang, X. X., Kosier, B., and Priefer, U. B. (2001). Symbiotic plasmid rearrangement in Rhizobium leguminosarum bv. viciae VF39SM. J. Bacteriol. 183, 2141-2144. doi: 10.1128/JB.183.6.2141-2144.2001

Conflict of Interest: The authors declare that the research was conducted in the absence of any commercial or financial relationships that could be construed as a potential conflict of interest.

Publisher's Note: All claims expressed in this article are solely those of the authors and do not necessarily represent those of their affiliated organizations, or those of the publisher, the editors and the reviewers. Any product that may be evaluated in this article, or claim that may be made by its manufacturer, is not guaranteed or endorsed by the publisher.

Copyright (C) 2021 Boivin, Mahé, Debellé, Pervent, Tancelin, Tauzin, Wielbo, Mazurier, Young and Lepetit. This is an open-access article distributed under the terms of the Creative Commons Attribution License (CC BY). The use, distribution or reproduction in other forums is permitted, provided the original author(s) and the copyright owner(s) are credited and that the original publication in this journal is cited, in accordance with accepted academic practice. No use, distribution or reproduction is permitted which does not comply with these terms. 